\title{
An Observational Study to Assess the Level of Satisfection Amongst Patients Operated As Elective Basis in Department of Surgery, G.R. Medical College \& Ja Group of Hospitals
}

\author{
Dr Darpan Toke*,Dr Ashish Gupta ${ }^{\varepsilon}$, Dr Achal Gupta ${ }^{p}$ \\ *Resident, Department Of Surgery, Grmedical College And JA Group Of Hospitals \\ $\varepsilon$ Assistant Professor, Department Of Surgery, Grmedical College And JA Group Of Hospitals \\ P Prof And Head, Department Of Surgery, Grmedical College And JA Group Of Hospitals
}

\section{Introduction}

Health as defined by WHO ${ }^{1}$ "is a state of complete physical, mental and social well-being and not merely the absence of disease or infirmity". Similarly health system, also sometimes referred to as health care system or healthcare system, is the organization of people, institutions, and resources that deliver health care services to meet the health needs of target populations. Patient satisfaction is a critical health care outcome indicator and should be given focus by the hospital administrators. From a management perspective, patient satisfaction with health care is important for several reasons ${ }^{2}$. First, satisfied patients are more likely to maintain a consistent relationship with a specific provider. Second, by identifying sources of patient dissatisfaction, an organization can address system weaknesses, thus improving its risk management. Third, satisfied patients are more likely to follow specific medical regimens and treatment plans. Finally, patient satisfaction measurement adds important information on system performance, thus contributing to the organization's total quality management. Provision of services in line with the wishes and needs of patients is central to a humane health care system. Society has long acknowledged the importance of the views of public in developing the very services provided to them ${ }^{[3]}$ and in the case of the health care system, patients have been found to be aware of health issues to the extent that they have been described as "expert witnesses" to the health care process ${ }^{[4,5]}$.

Hence over the past decade there has been increasing realization of the need to take into account patient reports of their hospital experiences in the development of action plans for improvement of services, safety and care provided. It is suggested that efforts to improve health care will be wasted unless they reflect what patients want from the service ${ }^{[6]}$. A variety of methods have therefore been employed to assess the patients' preferences for care, evaluations of what occurred, or factual reports of care. Examples are questionnaires to assess patients' needs before a consultation with the clinician, shared decision making, focus groups with patients to include their views in clinical guidelines, and surveys among patients to provide feed- back to care providers or the public. Development of newer tools and techniques to assess patient opinion is an emerging trend around the globe with the UK Patient's Charter and the review of the NHS highlighting the need for providers of hospital care to assess and improve the quality of care they offer, and to continue expanding their use of questionnaires and surveys. India has been in the forefront of various international movements in the health and population sectors. The overall Indian Healthcare Industry is going through a transition and the future is likely to see significant changes in the provision of healthcare and the roles of various players in the industry. The healthcare service scenario in India is expected to evolve into a more developed stage. With this transition, management of human resources in health is a major challenge to health systems development in India. The role of manpower plays a very important role in the hospital and every employee of the organization (hospital) vis-à- vis doctors, nurses, paramedical and non-technical staff has a direct or indirect involvement in rendering services to the patients ${ }^{[7]}$.

This trend, however, has still not picked up in developing countries like India, where most of the 'patient satisfaction studies' still focus on specific areas such as the emergency department, day care surgery or family medicine sections of the hospital. A study is thus required to survey patients' opinions of general aspects of inpatient care provided to them during hospitalization. Such a study becomes even more important in light of the limited budget allocation to the health sector in India and the inability of many patients to afford expensive treatment modalities. Hence there is further need to prioritize spending and this study hopes to fill this void by production of data that can help admintrators and doctors to identify and address unsatisfactory factors in the care they provide. As a tertiary level hospital \& teaching institute who serve populations of Gwalior \& nearby areas of Morena, Bhind, Datia, Sheopur, Shivpuri, Jhansi etc patient satisfaction is one of the important indicators as quality control for health services provided. Thus objective of the study is to determine the factors which affect patient satisfaction 
in surgical ward of our hospital that provides important information to hospital administration to improve patient care thus improve patient satisfaction.

\section{Aims And Objectives}

This study was conducted in Department of Surgery, G.R. Medical College and J.A. Group of Hospitals, Gwalior with the following aims and objectives:

To assess level of satisfaction amongst patients who have operated as elective basis in department of surgery, G.R. Medical College \& JA Group of Hospitals.

To know about the area of dissatisfaction with care $\&$ services provided to patients. satisfaction.

To suggest recommendations to organization in order to increase patients health care, confidence \&

\section{Customer And Patient Satisfaction}

\section{Review Of Literature}

Whenever either the customer is pleased with the product or the service then it is considered as satisfaction. Satisfaction may be a person's feelings of happiness or disappointment in result for comparing a product/service perceived performance or outcome with its expectation ${ }^{[8]}$. Satisfaction can be derived as happiness achieved from the consumption of goods or services offered by a person or group of people or it may be state of being happy with the situation.

Sometimes it becomes very difficult to satisfy everyone or determine satisfaction among group of individuals because mostly people have different perceptions and expectations. Satisfaction is similar to the other psychological words that are easy to understand but difficult to explain. The idea of satisfaction is similar to the themes such as happiness, contentment and good quality of life. Satisfaction is not the phenomenon waiting to be measured by people but is a judgment of people from over a period of time as they reflect from their experience ${ }^{[9]}$.

"A simple and practical definition of satisfaction would be the degree to which desired goals have been achieved" " ${ }^{[9]}$. Satisfaction can be said as a positive response of individuals to a specific focus (consumer experience) that is determined at a particular time ${ }^{[10]}$. For evaluating and making improvement in quality of health care, it is required to investigate the quality of care in the context of health care. Patient satisfaction is the substantial indicator in the health care. For this purpose, quality of work includes investigation that map out the patient satisfaction with several factors ${ }^{[11]}$. Patient satisfaction is used as performance of measurement by different hospitals, principally on instrumental grounds such as adhering to treatment, recommendations and maintaining continuity of care ${ }^{[12]}$.

Different professionals influence patient satisfaction. Health care practices are considered as the key factor in patient assessment of their satisfaction. The patient satisfaction assessment is important not only for patient but also for the health care organization as well ${ }^{[11]}$.

Patient satisfaction is fundamentally a subjective judgment that results from the appraisal of health care experience and involving the explicit and implicit comparison of the actual events with the expectation of the individuals. Patient satisfaction shows the degree to which the individual's actual experience matches with the preferences regarding their experience. Patient satisfaction is not only the judgment at the end of the care but also essential for the initial treatment decision for future ${ }^{[13]}$. As from the literature, we found that there is no exact definition of patient satisfaction because it depends on several factors. The main problem is that some patients are satisfied with one factor while the others are not. However Linder-Pelz suggest the definition of patient satisfaction through content analysis of the satisfaction studies in which five psychological variables were proposed to be probable determinant of satisfaction in health care services.

Occurrence: The outcomes of a result take place and importance of the individual perceiving what has been occurred.

Value: Judgment of the quality perceived as good or bad or features of health care encounter is consider by the customer as "value". Expectation: Patients belief that certain attributes might be attached to an object and judging importance of those attributes are the building blocks of satisfaction.

Interpersonal comparisons: Evaluating of the individual experience of current health care encounter with what he/she has experienced previously.

Entitlement: The individual thinking that he has a solid and sound basis for claiming of particular result. By evaluating these attributes the patient satisfaction definition becomes "the individual positive evaluation of distinct dimensions of health care" ${ }^{[14]}$.

Service quality-

Customer reaches the organization and benefit at the same time through services. Service can be defined in many ways depending on which area the term is being used. Kotler \& Keller ${ }^{[8]}$ defines service as "any intangible act or performance that one party offers to another that does not result in the ownership of 
anything". Service can also be defined as an intangible offer by one party to another with mutual consideration for pleasure.

Consumers mostly attracted towards a service by focusing on quality ${ }^{[15]}$. Another definition of quality is the total features and characteristics of a product or services that bear on its ability to satisfy stated or implied needs ${ }^{[8]}$. It is clear that quality is also related to the value of an offer, which could evoke satisfaction or dissatisfaction on the user's part. "A simple definition of quality in health care is the art of doing the right thing,

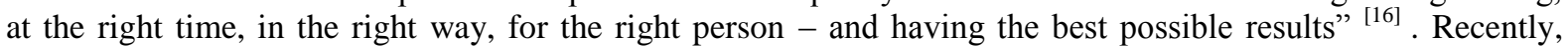
among health care researchers the greatest consensus has been achieved on the definition provided by Institute of Medicine (IOM): "quality of care is the degree to which health services for individuals and populations increase the likelihood of desired health outcomes and are consistent with current professional knowledge" [17].

According to Parasuraman et al. ${ }^{[12]}$ service quality is "the differences between customer expectations and perceptions of service". Measuring service quality to identify the difference between perceived and expected service is a valid way and enable the management to find gaps to what they offer as services. Organizations are now more focused on quality services and the aim is to satisfy customers. In order to know whether customer "will" is fulfill or satisfied, organizations need to measure the service quality, a better way to understand service quality in the context of customer satisfaction. A researcher listed in his study: "three components/dimensions of service quality, called the 3 "Ps" of service quality" ${ }^{[18]}$. The author explains in the study, service quality is comprised of three elements (Physical process, people's behavior, professional judgment):The overall technical facilities, process and procedures of an organization;

Staff behavior and responses towards their serving and; Staff efforts and professional judgments to improve quality of service

Haywood ${ }^{[18]}$ states, "an appropriate, carefully balanced mix of these three elements must be achieved." What constitutes an appropriate mix is determined by the relative degrees of service process customization, labour intensity, contact and interaction between the customer and the service process. However, this idea of the author could be evaluating service quality from the employee perspective. Researchers measure the service quality dimensions by using SERQUAL model that is the most popular and strong tool, also called gap model. Serqual model is created by Parasuraman et al. (1985) for the very first time and there were 97 attributes put into ten dimensions ${ }^{[19]}$. Through these dimensions, one can measure the customer satisfaction level regarding the quality of service of an organization. The findings became more interesting because of further investigation and concluded that, among these 10 dimensions, some were correlated. After some refinement, ten dimensions were later reduced to five dimensions ${ }^{[20]}$ :

Tangibility: This dimension consist of physical facilities, equipment, and appearance of personnel of an organization

Reliability: This dimension deals with the ability to perform the promised service dependably and accurately by the organization

Responsiveness: This dimension focuses on the willingness to help customers and provide prompt service

Assurance: This dimension explains how knowledge and courtesy of employees and their ability to inspire trust and confidence

Empathy: This dimension defines how much of an individualized attention the firm provides to its customers

From the above five dimensions perspective the aggregated sum of difference between perceptions and expectations global perceive quality construct is formed ${ }^{[20]}$. By these dimensions, quality of service can be improved and the customer satisfaction level can be increased. Service environment in the health-care industry is determined by not only technology and new facility support, but also the performance of employees in the organization. "Various methods and tools are used by medical administrators, researchers, and healthcare policy makers in an effort to find a better way to provide high quality of the service" ${ }^{\text {[21] }}$. Health care organizations need toemphasizes on every single aspect/dimension of service quality and not only on technology, facilities and support.

Health care organizations are now competing with each other especially in the patient satisfaction area. Patients can be satisfied through various combinations of responsiveness to the patient's views and needs, and continuous improvement of the healthcare services and in overall doctor-patients relationship. Health care providers are now more concerned with the patient satisfaction, as it is an important topic to understand and value by the patients. So in order to know how the patients perceive the quality of care and to know where, when and how service improvement can be made ${ }^{[16]}$. Health care providers are now more interested to know what factors/ dimensions can more affect the service quality, because of the high competition, extensive literature and pressure from the patients.

In the past, only few studies have been conducted in health care sector to investigate the link between technical and functional quality dimensions and the level of patient's satisfaction. Mostly the studies only focus on few aspects of health care quality of service but none of the studies has empirically examined how the 
atmosphere, interaction and infrastructure might affect the overall patient's quality perception and satisfaction. Patient satisfaction is a cumulative combination of different constructs, summing satisfaction with various facets of the health care organization (hospital), such as technical, functional, infrastructure, interaction and atmosphere variables or items ${ }^{[16]}$. Patient satisfaction regarding service quality is always dependent on different factors/dimensions and with the passage of time the factors/dimensions are explored by different researchers. Zineldin $^{[16]}$ expanded technical-functional and SERVQUAL quality models into framework of five quality dimensions, consist of quality of Object, quality of Process, quality of Infrastructure, quality of Interaction and quality of Atmosphere. This model is now considered an effective model for health care providers in order to evaluate patient's satisfaction.

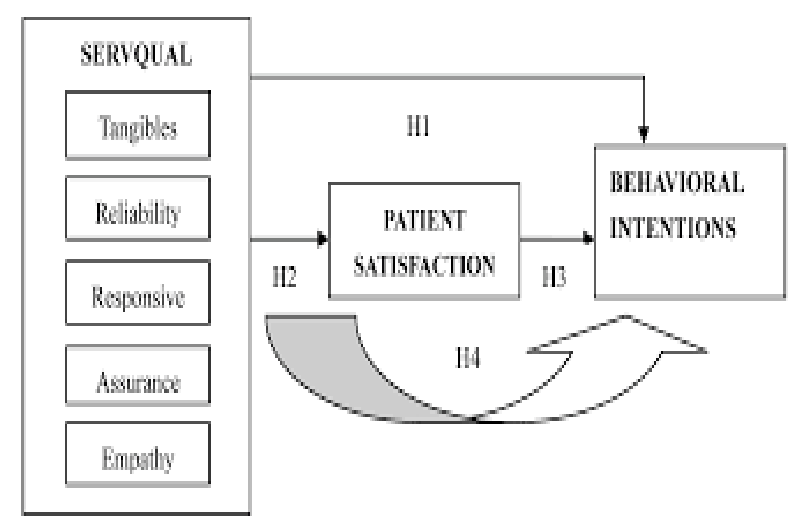

5Qs model: The health care service quality is not only affected by the technical and functional activities of the organizations but some other factors the researchers have

ignored, play an important role such as interaction, infrastructure and atmosphere. Zineldin (2000a) expanded technical-functional and SERVQUAL quality models into framework of five quality dimensions (5Qs): [16] Zineldin designed and developed a comprehensive model regarding patient satisfaction from health care providers, also called the 5Q model.

Q1. Quality of object - The technical quality (what customer receives), for example, relates to the clinical procedures carried out and it focuses on the technical accuracy of medical diagnosis and procedures. This dimension of service quality measures the treatment itself; the main reason of why a patient is visiting a hospital in the context of his very basic need and want.

Q2. Quality of processes - This dimension deals with the functional quality that how the health care organization provides the core service (the technical). This dimension measures how well activities of the health care are implemented practically. It includes waiting times by the patients and speed of performing the health care activities by the staff. Sensitive issues are attached to the health care industry so process indicators should receive more attention. These indicators can be used to identify problems in service delivery and to suggest specific solutions. Front-line nurses/physicians/managers can use process indicators to supervise/monitor activity at their facilities and to improve day-to-day decision-making.

Q3. Quality of infrastructure - This dimension of service quality measures the essential and basic resources that are needed to perform the health care services. This includes many attributes such as the quality of the internal competence and skills, know-how, experience, motivation, attitudes, technology, internal relationships, internal resources and activities and most important how these activities are managed, cooperated and coordinated. Researchers found that technology infrastructure can play a vital role in patient satisfaction and it has become a revolutionary key factor practicing in health care organization.

Q4. Quality of interaction - communication/interaction among the people is always difficult to deal with. It is not communication/interaction among the machines, accounting systems or trading agreements, which can do it effectively with each other in order to exchange values. This dimension of service quality measures the quality of information exchange (e.g., the percentage of patients who are informed when to return for a check-up, amount of time spent by physicians or nurses to understand the patient's needs, etc.), and social exchange, etc. Perceived quality of interaction and communication reflects a patient's level of overall satisfaction.

Q5. Quality of atmosphere - This dimension is concerned with the relationship and interaction process between the two parties is influenced by the quality of the atmosphere in a specific environment where they cooperate and operate. The atmosphere indicators should be considered very critical and important because of the belief that lack of frankly and friendly atmosphere explains poor quality of care (Zineldin 2006, p 69-71). 


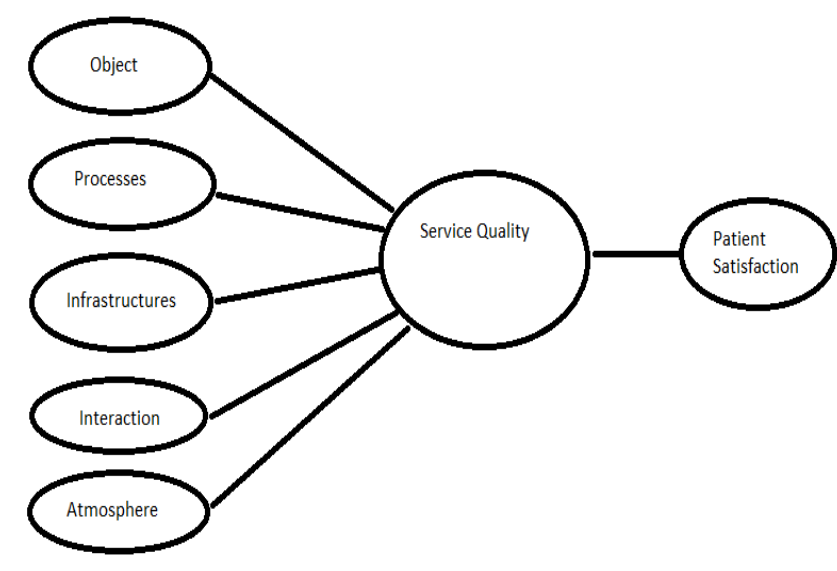

Above figure illustrates the 5Qs model and its constructs, where the service quality of the health care is function of Q1-Q5. The model consists of 5 dimensions of the service quality, all together 5 dimensions result in health care service quality which can affect the level of patient satisfaction ${ }^{[16]}$. According to Zineldin, all the dimensions are functions of service quality, which leads the patient to satisfaction.

Trust-

Generally, trust in the society can be viewed as the source of minimizing the complexity and means of coping with the freedom of others, trust is the feature of all social relationship and indicates some form of expectation about the future ${ }^{[22]}$. While trust can be also defined as depending on the characteristics of object, or the occurrence of an event, or the behavior of a person to organize the desired but uncertain objectives in a risky situation ${ }^{[23]}$. According to Mayer et al, (1995) ${ }^{[20]}$ trust is when one party willingly puts itself vulnerable to the other party and first one expect that the other party will do better in his favor, irrespective of the ability to monitor or control the other party.

Some researchers tried to define trust as, it is essential for effective interpersonal relations and community living ${ }^{[24]}$. Trust is the reliable source among people living in a society, as Thom et al. ${ }^{[25]}$ stated that trust is the acceptance in risky circumstances in which the trusters believe that the trustee will act in the best interest of truster. This kind of definition is supported by Hall et al. ${ }^{[18]}$ perceiving the hope in vulnerable situation by the trusters that trustee will care for the trusters interest. Mechanic \& Meyer ${ }^{[24]}$ defines that trust allows accepting vulnerability or the belief that the other has one best interest at hearts.

Hall et al ${ }^{[18]}$ further explored that trust cannot be separated from the vulnerability because in the absence of vulnerability there is no need of trust. The greater the situation of risk the greater will be the possibilities of trust or distrust. Trust can be also defined as to create the vulnerability as in the friendly relationship but vulnerability is prime and necessary in medicine, so it is important to think of trust in vulnerable conditions. Trust builds from the patients needs for physicians where greater the sense of vulnerability the higher will be potential for trust. Davies \& Randall ${ }^{[26]}$ differentiates between trust and faith that the nature of trust is different from dependency and faith. Trust develops between two parties under several conditions. First there must be some interdependency between them that is the action of one must have impact on the others. Secondly, there must be some choices selected by any party and thirdly, there must be some uncertainty or risk attached to these choices. In such a situation, one or both parties can place trust on each other and choose that other party will act in the best interest of them. The word choice has important role in trust because it gives way to risk and with this trust has dependency. However, the ones trust on another must be based on experience and knowledge of the other party that it has the competences and willingness to act on behalf of him. Trust without such experience and knowledge may regard as faith or hope.

According to Hall et al. ${ }^{[26]}$ trust by nature has different types and objects of multiple dimensions in which some of them focus on particular act or obligations while others stress personal attributes or characteristics. Instead of having these kinds of different conceptual schemes, it consists of some common dimensions that are fidelity, competence, honesty, confidentiality and global trust.

Fidelity: Fidelity is, pursing in the best interest of patients and avoiding the advantage of patient's vulnerability. It can be expressed by agency or loyalty, which consists of caring, respect, advocacy and prevents the conflict of interest. Caring and respect are the important elements, which are directly related to perception of motivation. Advocacy requires actions or we can say maintaining a positive thinking. For minimizing the conflict between the patients and physicians is considering the interest of the patient instead of other competitors. 
Competence: Competence means minimizing the mistakes and creating better achievable results. Mistakes may be cognitive which errors in judgments are while it may be technical which errors in executions are. Normally the patient faces difficulty in differentiating the technical competence so their views of competence are inclined by the physician interpersonal competence (communication skills and bedside manner). Conceptually and empirically it is valued to differentiate between the measure of trust and predictors of trust which is ultimately known as what trust is and what influence trust. However, communication includes eye contact, which is not effective in the caring directly because it does not make any correct sense that physician has good eye contact while it may also give way to misunderstanding. Alternative to this communication has great importance in perceiving their physicians skills, care and other personal characteristics.

Honesty: This dimensions suggest of telling the truth and minimize the intentionally falsehood. Dishonesty concludes telling a lie, half-truth and deceiving by silence. Dishonesty can be classified according to whom take advantage from this: (1) the physician who is unable to accept the mistake, (2) the patients who are expecting false hope and (3) is the institution, which covers the process, criteria for making the important decisions. Some of dishonesty includes the misleading of patient from the risk of treatment by encouraging them for beneficial treatment or discouraging from the expensive treatment. However, honesty sometimes lowers the trust in other dimensions which directly make the overall trust uncertain.

Confidentiality: Confidentiality promotes the proper use of responsive and secret information. This information is not use as secrecy but aim is to make useful for the proper treatment of patient. The main sources of leaking this information are physicians, medical personal and those who keep the medical records. The disclosing of information can be harmful as economically and personally while inappropriate or disrespectful information exchange among medical personal are the source of leaking information.

Fidelity: Fidelity is, pursing in the best interest of patients and avoiding the advantage of patient's vulnerability. It can be expressed by agency or loyalty, which consists of caring, respect, advocacy and prevents the conflict of interest. Caring and respect are the important elements, which are directly related to perception of motivation. Advocacy requires actions or we can say maintaining a positive thinking. For minimizing the conflict between the patients and physicians is considering the interest of the patient instead of other competitors.

Competence: Competence means minimizing the mistakes and creating better achievable results. Mistakes may be cognitive which errors in judgments are while it may be technical which errors in executions are. Normally the patient faces difficulty in differentiating the technical competence so their views of competence are inclined by the physician interpersonal competence (communication skills and bedside manner). Conceptually and empirically it is valued to differentiate between the measure of trust and predictors of trust which is ultimately known as what trust is and what influence trust. However, communication includes eye contact, which is not effective in the caring directly because it does not make any correct sense that physician has good eye contact while it may also give way to misunderstanding. Alternative to this communication has great importance in perceiving their physicians skills, care and other personal characteristics.

Honesty: This dimensions suggest of telling the truth and minimize the intentionally falsehood. Dishonesty concludes telling a lie, half-truth and deceiving by silence. Dishonesty can be classified according to whom take advantage from this: (1) the physician who is unable to accept the mistake, (2) the patients who are expecting false hope and (3) is the institution, which covers the process, criteria for making the important decisions. Some of dishonesty includes the misleading of patient from the risk of treatment by encouraging them for beneficial treatment or discouraging from the expensive treatment. However, honesty sometimes lowers the trust in other dimensions which directly make the overall trust uncertain.

Confidentiality: Confidentiality promotes the proper use of responsive and secret information. This information is not use as secrecy but aim is to make useful for the proper treatment of patient. The main sources of leaking this information are physicians, medical personal and those who keep the medical records. The disclosing of information can be harmful as economically and personally while inappropriate or disrespectful information exchange among medical personal are the source of leaking information.

Global trust: Global trust has ability of concerning strong connection with several other areas but does not fit exclusively in one. Global trust has important role in the component of trust, which is irreducible or we can say the "soul of trust" ${ }^{[18]}$. Mechanic \& Meyer ${ }^{[24]}$ further explains "Trust means compassion: it means listening and really hearing, it is just dedications". Trust means perceiving confidence in a person that will do the right thing in best interest of patients, perceiving the physicians is well trained and having experience worked on this type of medical problem, very well know how the latest technology and latest research, and treat all the patient in the same manner. Trust means that you would trust a person with your own well-being and in your absence that person is able to control the situation and you have a trust that the person will do the best in your interests. Trust creates the environment in which patient disclosures and cooperates in treatment, making easier to adjust unhealthy behavior as well as minimize the chance of complaints, disputes and lawsuits. Trust and openness of communication not only increases the human sensibilities of both patient and doctors, however 
increases the quality of interactions as well. For important personal relationship trust is the investment for the continuing possibilities of human learning and growth ${ }^{[24]}$. However, trust in medical profession is said to be exclusively related to the patient's desires of seeking care in terms of control by physicians in making medical decisions ${ }^{[27]}$. Trust can be a defining characteristic of the relationship between patients with their physicians and other care providers. Trust in the physicians is one of the strongest predictors of patient decision for enrolling in their treatment of any diseases. Mostly the patient trust is linked to proposed or reported patients devotion to treatment recommendations ${ }^{[12]}$. Interpersonal physicians trust is based on patient personal experience and physicians characteristics ${ }^{[27]}$. Factors in trust through which interpersonal trust increases among patients and physicians are, greater perception of mutual interest, clear communication, history of having fulfilled trust, low perception of power difference among the person being trusted, accepting the personal disclosure and expectation of the long term relationship ${ }^{[11]}$. "Trust is a lubricant that enables relationship to functions smoothly, a glue that binds people in mutually rewarding relationship and a stimulant that allows greater creativity, innovations and performance" ${ }^{[26]}$. Creating and maintaining trust is very difficult task because it needs repeated interactions and reliable experience. There is contradiction between trust and distrust, trust take long time to build but it can be destroyed easily and once it has been lost it become very difficult to rebuild it. Reputation-

Herbig \& Milewicz ${ }^{[28]}$ explains corporate reputation is trust that the corporate creates by keeping its promises in a decided manner. Consumers understand the importance of reputation and credibility. Whether to believe the product claims made by a manufacturer's advertising, credit check/verification for a new account, or whether to believe delivery dates or claims made by a vendor can be the examples from daily life usually we face. The estimated consistency of an attribute of entity overtime is called reputation. This estimation is based on the willingness and ability of the entity to perform an activity repeatedly in a similar fashion. An attribute is some specific part of the entity -price, quality and marketing skills. Aggregate composite of a historical notion of the entity, all previous transactions over the life of the entity, and requires consistency of an entity's actions over a prolonged time, cumulatively all together can be consider as a reputation. Reputation is established by the exchange of information from one user to another. Therefore, it is necessary that transactions between the entity and other parties must have occurred in order to establish a reputation and to value the transaction. Mostly reputation develops when entities are unsure or unaware about one another's options or motives and where they deal with each other repeatedly in related circumstances or past dealings observable with other firms ${ }^{[28]}$. Past performance always matters while dealing with customers; firms profile is observable in terms of services, quality, information and word of mouth continuously by the customers. Herbig \& Milewicz ${ }^{[28]}$ argued that reputation is a precious and valuable commodity, it takes time to build and need continuous improvement to maintain. If a firm provides accurate information to the customers, instead of making a user duping although firms made a short term loss but it can enhance its reputation by providing accurate information, which is a long term gain. Therefore, the company takes short term losses to build reputation and secure larger long-term gains. It is also fragile because the impact of a bad action on the customer is much stronger than that of a good action. Repeated positive transactions of a firm lead the firm to a positive reputation (for example, for quality or ontime delivery) and the same if a firm repeated negative transactions lead it to the negative reputation (poor quality or tardy deliveries). Any organization achieves a good overall reputation and owns a valuable asset "goodwill": brand names, corporate logos and customer loyalty. However, it should be kept in mind that reputation is fragile and sensitive. It can be lost easily and once it is lost, it takes much time and effort to build it again. In order to restore reputation organization requires seven to ten times' more efforts as compared to before it was lost. Organizations with vision to build and maintain a long term reputation they need to deliver the promised quality of the good/service (so as not to make worthless its prior investment or to incur the new cost of regaining it). The cost of establishing a reputation and the cost of maintaining this reputation is an investment the firm recoups through charging or receiving a premium ${ }^{[28]}$. Reputation is a long-term process to build and once establishes, it needs more attention to maintain it.

Bromley ${ }^{[29]}$ define reputation as the collective assessment of a firm past behavior and outcomes that deliver the firm's ability to render valued results to customers. Reputation thus reflects the relative standing/position, internally with the employees and externally with the different stockholders. Every organization, especially health care providers should consider reputation as vital as Hibbard et al. ${ }^{[30]}$ argued that if a hospital reputation is affected due to some attributes then it might declines its market share via patient choice, purchase choice, or physician referral. Also declining reputation may bring other challenges to the organization such as recruiting and retaining staff and at the same time affect a hospital ability to maintain legitimacy and professional standing.

Organizations have different and various reasons to be concerned about their reputations. It is very clear that the most motivating factor is a professional pride, but change in reputation of health care organizations can influence financial and overall performance. Negative reputation could affect hospital's ability to raise funds, charitable donations that are important sources of income for not-for-profit health care organizations and 
for the public health care organizations. Moreover, it is difficult to obtain budgets from the state in case of negative reputation ${ }^{[30]}$.

Reputation in the health care organizations is affected by experience - stakeholders with more experience probably know the organization better and can thus evaluate it more accurately. That is why researchers suggest that health care organizations need to enhance the quality of the care delivered to patients and effectively perform to the communities in which they operate ${ }^{[31]}$.

Since the service is human health, how the reputation perceived is important. In parallel to this, since the patients get treatment at health care organizations towards their preferences, it is important to measure the reputation depending on customer/patients perceptions [31]. According to Herbig \& Milewicz [28], an organization's reputation is consisting of trust that the organizations establishes it by keeping its promises and fulfill it in time, Satir ${ }^{[31]}$ illustrates the following dimensions to affect customers/patients perceptions of corporate reputation, service quality and, communication. Research by Power ${ }^{[33]}$ states the importance of a positive reputation to a hospital, as patients now have more choices in the health care providers they can choose. Because of this, hospitals need to continue to enhance the clinical and experimental quality of the patient care and effectively communicates their performance in the communities they serve.

Satisfaction is derivable when there is alignment between patients' perspective on what constitutes satisfaction in health care and the providers view ${ }^{[34]}$;

Initially, these patient satisfaction surveys typically asked patients to rate their satisfaction with various aspects of hospital services. In the 1990s, patient satisfaction surveys became quite common, but were often been criticised on the basis of conceptual problems and methodological weaknesses (see, for example, Hall and Dornan 1988; Aharony and Strasser 1993; Carr-Hill 1992; Williams 1994; Draper and Hill 1995; Sitzia and Wood 1997). Several conceptual and methodological issues were identified.

Satisfaction is a multi-dimensional construct. There is limited agreement on what are the dimensions of satisfaction, and a poor understanding of what overall ratings actually mean.

Surveys typically report high levels of overall satisfaction (rates that are similar across a broad range of industries), but often there is some disparity between the overall satisfaction ratings, and the same patients' opinions of specific aspects of their care process (Draper and Hill 1995).

Survey approaches have often reflected the concerns of administrators and clinicians rather than reflecting what is most important to patients.

Satisfaction ratings are affected by: the personal preferences of the patient; the patient's expectations; and the care received.

Systematic biases have been noted in survey results — for example, older patients are generally more satisfied with their hospital experience than younger patients; patients with lower socio-economic circumstances are generally more satisfied than wealthier patients.

One response to these criticisms has been the development of survey approaches that assess actual patient experiences. It is argued that this enables a more direct link to actions required to improve quality (see, for example, Cleary 1993). This is one of the underlying philosophies of the Picker organisation. A qualitative research program involving researchers at Harvard Medical School was implemented to identify what patients value about their experience of receiving health care and what they considered unacceptable. Various survey instruments were then designed to capture patients' reports about concrete aspects of their experience. The program identified eight dimensions of patient-centred care: Access (including time spent waiting for admission or time between admission and allocation to a bed in a ward)

Respect for patients' values, preferences and expressed needs (including impact of illness and treatment on quality of life, involvement in decision making, dignity, needs and autonomy)

Coordination and integration of care (including clinical care, ancillary and support services, and 'frontline' care)

Information, communication and education (including clinical status, progress and prognosis, processes of care, facilitation of autonomy, self-care and health promotion)

Physical comfort (including pain management, help with activities of daily living, surroundings and hospital environment)

Emotional support and alleviation of fear and anxiety (including clinical status, treatment and prognosis, impact of illness on self and family, financial impact of illness)

Involvement of family and friends (including social and emotional support, involvement in decision making, support for care giving, impact on family dynamics and functioning

Transition and continuity (including information about medication and danger signals to look out for after leaving hospital, coordination and discharge planning, clinical, social, physical and financial support).

The Picker approach (based on these eight dimensions) has subsequently formed the basis of the United Kingdom's NHS patient survey and was adapted for some surveys in Australia in previous years. 
Since 1998, the United Kingdom's NHS has mandated a range of surveys including surveys of acute inpatients. National survey instruments have been developed with the Picker Institute in Europe. Whilst the surveys are centrally developed and accompanied by detailed guidance, they are generally implemented locally by individual healthcare organisations. Results from previous surveys are published and form part of the rating systems using for assessing health service performance across England. For this project the latest survey instrument for acute inpatients was analysed (see appendix E).

Another important international initiative (yet to be finalised) is the development of the HospitalConsumer Assessment of Health Plans Survey (H-CAHPS) in the United States. The Consumer Assessment of Health Plans (CAHPS) was originally developed for assessing health insurance plans. The development occurred under the auspices of the US Agency for Healthcare Research and Quality (AHRQ), which has provided considerable resources to ensure a scientifically based instrument. The work on CAHPS was originally published in 1995 along with design principles that would guide the process of survey design and development.

CAHPS instruments go through iterative rounds of cognitive testing, rigorous field testing, and process and outcome evaluations in the settings where they would be used. Instruments are revised after each round of testing. Various CAHPS instruments were subsequently adopted widely across the US.

The H-CAHPS initiative has occurred as a result of a request from the Centres for Medicare and Medicaid for a hospital patient survey which can yield comparative information for consumers who need to select a hospital and as a way of encouraging accountability of hospitals for the care they provide. Whilst the main purposes of H-CAHPS are consumer choice and hospital accountability, AHRQ states that the instrument could also provide a foundation for quality improvement. The H-CAHPS survey will capture reports and ratings of patients' hospital experience. AHRQ has indicated that ... as indicated in the literature, patient satisfaction surveys continually yield high satisfaction rates that tend to provide little information in the way of comparisons between hospitals. Patient experiences tend to uncover patient concerns about their hospital stay, which can be of value to the hospitals (in quality improvement efforts) as well as consumers (for hospital selection). For this paper, a draft version of the H-CAHPS instrument (see appendix D) has been compared with the various Australian survey instruments.

In the World Health Report 2000, the WHO presented a framework for assessing health system performance. The framework identified health system responsiveness as an important component of health system performance. Responsiveness is conceptualised as the way in which individuals are treated and the environment within which they are treated ${ }^{[35]}$. The WHO identified eight dimensions of responsiveness:

Respect for autonomy

Choice of care provider

Respect for confidentiality

Communication

Respect for dignity

Access to prompt attention

Quality of basic amenities and

Access to family and community support.

Sitzia, J. and Wood, N. (1997). Patient Satisfaction: A Review of Issues and Concepts. Social Science and Medicine, 45: 1829-1843.

Sitzia and Wood review the literature and suggest that patient satisfaction could be assessed by measuring 1) the degree to which patients believe that care possesses certain attributes and 2) the patient's evaluation of those attributes. They suggest that satisfaction is not single concept made up of multiple determinants, but that there exists three independent models of satisfaction, each associated with one determinant. Thus, there is the "need for the familiar," the "goals of help-seeking" and the "importance of emotional needs." Furthermore, there is evidence that there are two states of satisfaction, stable ones related to health care generally and dynamic ones related to specific health care interactions. Components of satisfaction consist of: structural, technical and interpersonal aspects of care.

Expectations are critical as they form the basis for the subjective assessment of care that is the rating of satisfaction. There can be different expectations for different aspects of care and patients with lower expectations tend to be more satisfied. Satisfaction cannot be interpreted as a measure of quality of care and must be interpreted in the context. The determinants of satisfaction are expectations, patient characteristics, and psychosocial determinants.

The structural aspects includes: access, physical setting, costs, convenience, treatment by non-clinical staff/insurers. The technical aspects includes knowledge, competence/quality of care, interventions, outcomes. The interpersonal aspects includes: communication, empathy, and education.

The "discrepancy model" posits that the general lack of variability in patient satisfaction scores indicates that researchers should explore what explains dissatisfaction, and not satisfaction. 
Hall, J. and Dornan, M. (1990). Patient Sociodemographic Characteristics as Predictors of Satisfaction with Medical Care: A Meta-Analysis. Social Science and Medicine; 30(7): 811-818.

This paper reviews the evidence of the relationship between patient satisfaction and patient characteristics using quantitative meta-analytic techniques. The authors used standard and accepted methods for identifying published quantitative analyses of patient satisfaction where information on the association among patient characteristics and satisfaction were presented. One hundred and ten published reports were included in the analysis that met the authors' criteria for inclusion. For each study, each correlation was extracted and coded as to which of the 11 aspects of care it pertained to; the 11 aspects of care were: access, cost, overall quality of care, humaneness of providers, competence of providers, information given by providers, bureaucracy, physical facilities, providers' attention to psychosocial problem, continuity of care and outcome of care. More satisfied patients tended to be older, white, male and of higher social class, and married.

The paper also reports several interesting contrasts among variables, such as sex and ethnicity. The authors conclude by stating that in overall terms, it appears that patient satisfaction is associated with age and education and nearly significantly associated with social and marital status. The authors continue to state that the associations may be due to response patterns on the part of the groups identified or they may be mediated by events and processes that occur during the medical care encounter.

Inui, T. and Carter, W. (1985). Problems and Prospects for Health Services Research on ProviderPatient Communication. Medical Care; 23(5): 521-538.

In this review of studies of provider-patient communication, the authors assert that even with the vast knowledge available on biological processes and disease mechanisms, communication between health care provider and patient is an extremely important aspect of health care. Attempting to measure this, however, requires interdisciplinary activities, since merely measuring satisfaction at the conclusion of an interaction cannot measure all the nuances of communication (both verbal and non-verbal). They then spend some time describing the methods of systematic analysis of these interactions, citing that many of the methods have generic similarities: strategies utilized direct observation; emphasis on specific processes such as verbal communication; multiple classifications to categorize encounters; and an approach to quantify the events. The authors also argue that it is important to understand pre-encounter state in order to place post-encounter measures into perspective. This could include patient expectations of the encounter, degree of prior exposure to the health care provider, and demographic characteristics, all of which can ultimately effect how a patient interprets the encounter. The authors conclude that it is important to augment measures that categorize a specific type of interaction (the example they gave was verbal communication) with measures of other types of interaction, such as body language. They also point out that for chronic diseases, addressing symptoms and providing support rather than a "cure" is often the goal, once again pointing to the importance of communicating effectively with patients through the course of their treatment.

Hall, J., and Dornan, M. (1988). Meta-Analysis of Satisfaction with Medical Care: Description of Research Domain and Analysis of Overall Satisfaction Levels. Social Science and Medicine; 27(6): 637-644.

The authors conducted a meta-analysis of 221 studies to examine consumer satisfaction with medical care. The authors begin by describing the general characteristics that could describe satisfaction instruments. Directness of the question relates to how directly a patient was asked about their satisfaction (how satisfied were you vs. describe the care you received). Specificity refers to how general of an encounter is being measured, ranging from measures of a health system in general to measures of a specific visit. Type of care refers to the type of service being accessed (e.g. ambulatory care). Dimensionality refers to the aspects of the care being measured (e.g. humaneness of provider). Overall, most studies in the meta-analysis had high rates of satisfaction.

Other results discussed included: patients were more satisfied with physicians with less experience; general satisfaction studies had lower satisfaction ratings than specific event focused studies; and higher satisfaction levels were found when utilizing patients from a health system rather than a community sample.

The authors then present theories for results found. Presumably patients were more satisfied with newer doctors because they spend more time with patients, and displayed more technical and interpersonal competence (supported by other literature). They presented several hypotheses for why more specific encounters were rated higher than studies focusing on satisfaction with health care in general. The first is related to temporality and cognitive process, in that negative experiences are remembered for a longer period of time. Since most general satisfaction surveys were not administered immediately after an encounter, they may be influenced by the more negative experiences of those being interviewed. Additionally, general satisfaction survey respondents may draw on more generic (and potentially negative) views of health care rather than a specific encounter with a health care provider, whereas patients' evaluations of "my care" specifically may have more positive views. In either case, these attitudes and perceptions could skew the results.

McDaniel, C. and Nash, J. (1990). Compendium of instruments measuring patient satisfaction with nursing care. Quality Review Bulletin; 182-188. 
The authors summarize measures of patient satisfaction in nursing care. The authors utilized various techniques to compile a list of 21 instruments including: name of the tool, date developed and developer; purpose of the measure; a description of the measure; the psychometrics (reliability and validity) of the measure; and the availability of the measure.

Barr, D. and Vergun, P. (2000). Using a New Method of Gathering Patient Satisfaction Data to Assess the Effects of Organizational Factors on Primary Care Quality. Journal on Quality Improvement; 26(12): 713723.

The authors of this article argue that conventional methods of assessing patient satisfaction are insufficient. Traditionally, a survey (e.g. the nine-item Visit-Specific Satisfaction Questionnaire (VSQ)) is administered either after the encounter or by telephone at a later date. However, such instruments cannot capture the patient's perspectives of the encounter or objective measurements of the system. The authors developed a means of collecting this information via a 67-item questionnaire (included in the article) that collected patient demographic information and health status, prior health care (continuity), and ancillary services utilized by the patient. Targeted to patients coming to a primary care office visit at a large multispecialty facility in northern California, the study achieved a response rate of 77.6 percent for a total sample size of 291 .

Guyatt, G., Mitchell, A., Molloy, W., Capretta, R., Horsman, J., and Griffith, L. (1995). Measuring Patient and Relative Satisfaction with Level or Aggressiveness of Care and Involvement in Care Decisions in the Context of Life Threatening Illness. Journal of Clinical Epidemiology; 48: 1215-1224.

Researchers were attempting to develop a questionnaire that addressed two important aspects of patient and relative satisfaction with medical care: level of care received and the degree of involvement in healthcare decisions. Researchers generated items via literature reviews and interviews with patients, relatives of patients and healthcare providers, and included items in the final scale that were most identified as areas of dissatisfaction or of importance. Ultimately, three uni-dimensional 7-point ( 7 designated high satisfaction, 1 designated low) response scales were created: the 23-item Patient Satisfaction Index, the 34-item Relative of Competent Patient Satisfaction Index, and the 29-item Relative of Incompetent Patient Satisfaction Index.

The authors believe that their instruments measure satisfaction with the degree of participation in decision-making and satisfaction with the intensity of care provided" and hypothesize that the instruments may be appropriate for use with "younger chronically ill patients and their families".

Hall, J. and Dornan, M. (1988). What Patients Like About Their Medical Care and how often they are asked: A Meta-Analysis of the Satisfaction Literature. Social Science and Medicine; 27(9): 935-939.

The authors conducted a meta-analysis of 221 studies to addresses the multidimensionality in satisfaction instruments. The authors developed 12 categories of dimensions that were addressed across all the studies.

These were overall satisfaction; satisfaction with: access; cost; overall quality; humaneness; competence; the amount of information supplied by the provider; bureaucratic arrangements and members of the bureaucracy; physical facilities; the provider's attention to phychosocial problems of the patient; continuity of care; and the outcome of care.

The authors then created a measure of level of satisfaction for each dimension from available data from the studies. Results indicated that overall quality ranked the highest in terms of satisfaction and satisfaction with attention to psychosocial problems ranking the lowest. However, it should be noted that only 7 of the 221 studies addressed this dimension of satisfaction. A majority of studies (65 percent) addressed humaneness. The authors discussed interpretations of why the rankings of the dimensions were distributed as described in the paper (patients gave lower satisfaction ratings to dimensions not related to physical needs (e.g. need for information) or to the provider (e.g. cost, access)). One interpretation was that the satisfaction ratings are actually accurately measuring what they are supposed to-performance of the system as a whole, with patients satisfied with technical aspects related to the provider and less satisfied with system related aspects. Another interpretation was that patients did not feel qualified to access the technical abilities of the provider (though the authors cite other literature that suggests this may not be the case). The authors conclude by stating that the nature of the studies made it difficult to operationalize the concept of satisfaction. For example, even though it is known that psychosocial problems are an important aspect of health, few studies have included it when measuring satisfaction, limiting the utility of measures of satisfaction. They also note that there is little standardization across studies in terms of the actual measures utilized, making it difficult to generalize about satisfaction with health care.

Nelson-Zlupko, L., Morrison-Dore, M., Kaufman, E., and Kaltenbach, K. (1996). Women in Recovery: Their Perceptions of Treatment Effectiveness. Journal of Substance Abuse Treatment; 13(1): 51-59.

This paper examines women's perceptions and experiences of substance abuse treatment services in Philadelphia, PA. The authors begin by reviewing the research that calls for gender-specific treatment programs and the evidence that very little actually exists. Further, the existing research reveals little about what women themselves think about the services in terms of their helpfulness or lack thereof. In order to address these issues, 
the authors interviewed 24 women who had received specialized and non-specialized services about their perceptions about and experiences of the services. Both quantitative and qualitative approaches were used during a $1 \frac{1}{2}$ hour face-to-face, interview. Results indicated that the services that were perceived to be most helpful, transportation assistance, help obtaining food, clothes, etc., recreational activities, onsite health care, 12 step meetings and women's issues discussion groups, were often the least available.

Services that are often specific to women were unavailable much of the time.

For example, while women-only groups were available $56 \%$ percent of the time, onsite child care was available only $29 \%$ of the time and help obtaining child care only $21 \%$ of the time. From the qualitative data, several interesting themes emerged.

Women identified caring and respectful counselors as critical to their treatment continuation and recovery; outright sexual harassment and abuse is a problem for women in treatment settings; child care issues must be adequately addressed. Other themes that emerged centered on the importance of race/ethnicity, gender politics, and reproductive health care.

The authors conclude that "despite over a decade of research pointing to the need for gender sensitivity in drug treatment" female patients still receive inappropriate services and harmful treatment.

Linn, L. (1975). Factors Associated with Patient Evaluation of Health Care. Health and Society. Milbank Memorial Fund Quarterly Health and Society; 4: 531-548.

The author relates satisfaction with health insurance coverage, healthcare provider, and "new" (at the time) non-physician health care providers (e.g. physician's assistant), noting three commonalties in the research to date: there were high levels of patient satisfaction; there were inconsistent findings related to the relationship between social/cultural factors and satisfaction; and the relationship between patient satisfaction levels and specific medical encounter characteristics had not been identified.

This paper presents data for an investigation whose goals were to measure the level of patient satisfaction and determine the relationship between patient characteristics, health care encounter characteristics, and patient satisfaction. A total of 1,739 patient-provider encounters in eleven Southern California ambulatory health care settings were evaluated. Measures of patient encounters (e.g. general characteristics such as physician time spent with the patient; services performed, such as X-ray; and disposition of service), patient characteristics (e.g. age, sex, etc.) and patient satisfaction were collected. Two measures of patient satisfaction were utilized - the 6-item General Evaluation Index (attitudes towards the entire visit) and the 4-item Index of Satisfaction (encounters with physician). Results indicated high levels of patient satisfaction, consistent with prior research. There were also detailed findings related to the relationship between patient characteristics and the characteristics of the health care encounter, which are summarized later in this review.

Jackson, J., Chamberlin, J., and Kroenke, K. (2001). Predictors of Patient Satisfaction. Social Science and Medicine; 52(4): 609-620.

Correlates of patient satisfaction were measured over time. Participants were 500 patients presenting to the general medical care clinic of a large military (Walter Reed Medical Center) medical center. Patients were surveyed immediately before their medical care visit, immediately after the visit, and two-weeks and threemonths post-visit. Patient satisfaction was measured immediately post-visit with the Medical Outcomes Study (MOS) 9-item satisfaction scale that covered satisfaction with general and specific areas of care. At two-weeks post-visit patients were mailed a questionnaire that assessed satisfaction with only the general area of care. The Results indicated that immediately post-visit, just over half of all patients rated their overall care as excellent; these proportions increased to $59 \%$ at two-weeks post-visit and $63 \%$ by three-months post-visit. Multivariate analysis revealed that immediately post-visit satisfaction was associated with having no unmet expectations, receiving a causal explanation of symptoms, and being older than 65 .

These factors explained just $26 \%$ of the variance in patient satisfaction. At two-weeks and threemonths post visit, multivariate analysis revealed that satisfaction was associated with symptom improvement, reporting no residual expectation, neither requiring nor anticipating another doctor visit and improved function. These factors explained 38 and $40 \%$ of the variance in patient satisfaction scores at two-weeks and three-months post-visit.

The authors note that if patient satisfaction is assessed at any time later than immediately after the visit, then function and symptom-specific improvement should be taken into account and attention should be paid to the time intervals at which satisfaction is measured. The importance of symptom improvement was highlighted when comparing patients who were fully satisfied immediately after the visit and did not experience symptom improvement with those who were also satisfied post-visit and did experience symptom improvement. The latter group was significantly less satisfied than the former group. Conversely, patients less satisfied immediately post-visit, but whose symptoms improved were more satisfied at later time points as compared with those who were also less satisfied immediately post-visit and whose symptoms did not improve. Finally, while physician communication factors were significantly related to patient satisfaction immediately after the visit, by twoweeks and three-months post-visit, satisfaction was related to the course and impact of the underlying symptom. 
The authors conclude that satisfaction measures taken outside the context of a visit may be a proxy for functional status or symptom improvement.

Finally, they report that immediate post-visit satisfaction appears to be more associated with providerlevel communication factors than symptom factors, while patient age and function are associated at both time points. Brown, J., Boles, M., Mullooly, M., and Levison, W. (1999). Effects of Clinician Communication Skills Training on Patient Satisfaction: A Randomized, Controlled Trial. Annals of Internal Medicine; 131(11): 822829.

The purpose of this study was to test the effects of a common communication skills building program designed to increase physician's listening and communication skills on patient satisfaction ratings of provider communication during specific medical care encounters. The program consisted of a 10-hour, two-part training. Physicians were recruited from the Kaiser Permanente Northwest Division in Portland, Oregon and in the usual way for a continuing education program. Once providers indicated their interest in the course, they were invited to participate in the study; providers were assigned to the intervention or control group. The intervention group simply attended the program in advance of the control group. Patient satisfaction was assessed using the Art of Medicine Survey and assessed patients' satisfaction clinician. Anonymous self-administered questionnaires were sent to patients within 10 days of their visit to the ambulatory care facility; data were collected during one year in 1995 and 1996. General estimating equations were created, controlling for baseline patient satisfaction scores and results indicated that while patient satisfaction scores were higher among the intervention group, the difference was not statistically significant. Providers in the intervention group reported improvements in communication skills and lower frustration with visits. The authors concluded that while communication has been determined to be related to patient satisfaction it is unrealistic to expect a single brief continuing education course to improve general patient satisfaction in the "contemporary health care environment."

"Lengthened and intensified training, performance incentives, ongoing feedback and practice restructuring may all be needed before the broader benefits of improved communication can be realized."

Roter, D., Stewart, M., Putnam, S., Lipkin, M., Stiles, W., and Innui, T. (1997). Communication Patterns of Primary Care Physicians. JAMA; 277(4): 350-356.

The authors studied communication patterns and their relationships with patient satisfaction. Study participants were 127 physicians and 537 patients from 11 ambulatory care clinics and private practices in the US. Patient satisfaction was measured using a 43-item measure designed by the authors that taps 5 distinct and reliable dimensions of patient satisfaction: task-directed skill, attentiveness, interpersonal skill, emotional support, and physician-patient partnership. Communication patterns were analyzed using Roter Interactional Analysis System, an analysis system that codes phrases and complete thoughts into one or 34 exclusive and exhaustive categories. Results indicated that of visits fell into one of the following five provider communication patterns: narrowly biomedical, expanded biomedical, biopsychosocial, psychosocial and consumerist. Patient satisfaction was related to communication pattern; in multivariate models, patient satisfaction was significantly higher for patients in the psychosocial pattern of communication. The lowest ratings were for the narrowly and expanded biomedical model patterns, followed by the biopsychosocial and the consumerist. Interestingly physicians were also dissatisfied with the narrowly biomedical pattern of communication.

The authors conclude that communication patterns are critical to patient satisfaction.

Brody, D., Miller, S., Lerman, C., Smith, D., Lazzaro, C., and Blum, M. (1989). The Relationship between Patients' Satisfaction with Their Physicians and Perceptions about Interventions They Desired or Received. Medical Care; 27: 1027-1035.

The purpose of this study was to determine the relationship between patient satisfaction, intervention types and congruence between intervention types and desires for specific interventions. Study participants, 118 of 130 eligible adult symptomatic primary care patients, completed self-administered questionnaires immediately before and after the care encounter. Patient satisfaction was measured with the Ware Satisfaction Scale. Expected and desired interventions were assessed by asking patients to check off interventions from a list of possible interventions before the encounter and then having them indicate which intervention they had received after the visit. One-way ANOVAs were used to assess differences in levels of patient satisfaction among patients who received each type of intervention and those who did not and stepwise multiple regression was used to measure the relative impact of congruence on interventions on patient satisfaction ratings. Results indicated that patients who reported received any one of three non-technical interventions, education, stress counseling and discussing their ideas, were significantly more satisfied than those who did not receive such interventions. Those three variables explained, 13, 4 and $8 \%$ of the variance in patient satisfaction scores, respectively. None of the technical interventions were associated with patient satisfaction. In addition, patients often received the intervention the desired; when previsit desires were matched to interventions received, the following variables were associated with greater patient satisfaction: receiving negotiation, where it was not initially desired, receiving education, where it was initially desired, not receiving education, where it was initially desired, not receiving nondrug treatment, where it was initially desired, receiving and desiring stress 
counseling. Finally, when all nontechnical interventions were added to the model of patient satisfaction that included all technical intervention variables, they explained $23 \%$ of the variance; however, when technical intervention variables were added to the model of patient satisfaction that included all nontechnical interventions variables, there was no significant improvement in the model.

The authors conclude that that non-technical aspects of care drive patient satisfaction scores in part because: patients are unable to assess technical care; patients may perceive technical care as so uniformly good that there is very little variability; or that nontechnical aspects of care are simply more meaningful to patients.

Fox, J. and Storms, D. (1981). A Different Approach to Sociodemographic Predictors of Satisfaction with Health Care. Social Science and Medicine; 15A: 557-564.

The authors' discuss a theoretical model they have developed that could establish (and explain) the relationship between sociodemographic characteristics and satisfaction. They hypothesize that every individual has an assumption about what constitutes appropriate (and therefore high quality) health care. They also posit that health care providers also have orientations that manifest themselves in how they treat patients. It is when the patient's expectations for appropriate care are congruent with the health care provider's approach that we would expect to see high levels of satisfaction. They argue that these factors, rarely measured in studies, are modifying the relationship between sociodemographic characteristics and satisfaction, resulting in conflicting reports about the importance of sociodemographic characteristics to satisfaction. Thus, they hypothesized, controlling for patient expectations and health care provider orientation should better define the relationship between sociodemographic characteristics and satisfaction. To test this hypothesis, they interviewed (via telephone) 2582 (of 3398 in the sample - a response rate of 78 percent) residents who lived in the Baltimore metro area in late 1974 through early 1975. Respondents who reported receiving medical care within the prior 12 months were asked to rate their level of satisfaction with the medical care they received on a scale of 1 to 10 . 79.9 percent of the sample had received care in the designated period.

Results demonstrated that controlling for patient expectations and health care provider orientation resulted in all demographic variables becoming non-significant in the model, except age and gender.

The authors suggest that this is the case because these two variables are the strongest demographic predictors of utilization of health care. If validated further, the authors state that the model "may redefine the importance of the current methodological search for dimensions of satisfaction".

Carlson, M. and Gabriel, R. (2001). Patient Satisfaction, Use of Services, and One-Year Outcomes in Publicly Funded Substance Abuse Treatment. Psychiatric Services; 52(9): 1230-1236.

The primary purposes of this study were: to determine whether those in publicly funded substance abuse treatment received more treatment (i.e. participated more) if they were more satisfied with the services; and to determine whether satisfaction with services could predict other outcomes. The sample consisted of 310 patients in Oregon and Washington State (of 502 participants) who were interviewed three times, and had chart reviews conducted by the researchers. Satisfaction measures addressed satisfaction with: access to services, treatment effectiveness, and overall care (global measure). Dichotomous outcome measures were created covering the time period 30 days prior to the interview and included: abstinence from alcohol/drugs, presence of psychiatric symptoms, and employment. The chart review was utilized to measure service usage. As expected, satisfaction rates were high across the three measures. At six months, satisfaction with access and effectiveness predicted service use. There was a significant relationship between abstinence at one year and service use and satisfaction with access and effectiveness. Patient satisfaction was not related to other outcomes.

As the authors note "...this study suggests that patients who are more satisfied receive more therapy and are more likely to be abstinent from the use of alcohol or other drugs one year after starting treatment".

Ross, C., Steward, C., and Sinacore, J. (1993). The Importance of Patient Preferences in the Measurement of Health Care Satisfaction. Medical Care; 31(12): 1138-1149.

The authors of this paper theorize that one aspect of patient satisfaction that is not often measured-the patient's preference as to which patient care dimensions are most important — could be an important determinant of satisfaction with health care. They hypothesize that the linear compensatory model (i.e. overall satisfaction is comprised of multiple dimensions that may "compensate" for each other when some dimensions may be rated more highly than others based on patient preference) will be the basis for the relationship between satisfaction and patient preference, if one exists. A randomly selected sample of 308 patients seeking ambulatory services at a Veterans Hospital were identified as eligible for the study; ultimately 233 completed the interview. Patient satisfaction was measured utilizing the 29-item Patient Satisfaction Questionnaire (PSQ), which yields six dimensions of health care: access to care; availability of services; technical quality of care; interpersonal care; communication; financing of care; and overall satisfaction. The 138-item Sickness Impact Profile was used to measure psychological, physical and overall function due to health, and an importance ranking was developed to allow patients to prioritize their perceived importance of the six dimensions measured by the PSQ.

Utilizing stepwise multiple regression, the researchers determined that most of the variance in the model (63 percent) was due to three dimensions: interpersonal care, technical quality and access to care. 
In terms of preferences, four subgroups of patients were found: those who felt that interpersonal care was most important; those who thought access to and quality of care were most important; those who thought only access to care was important; and those who thought only quality of care was important.

Though there were some consistencies in terms of the relationships between these subgroups and satisfaction, the authors concluded that "patient satisfaction in this sample is best measured by quality evaluations of satisfaction dimensions without regard to preferences for care".

Kane, R., Maciejewski, M., and Finch, M. (1997). The Relationship of Patient Satisfaction with Care and Clinical Outcomes. Medical Care; 31(7): 714-730.

The authors of this study assert that patient satisfaction is not only important as an outcome of the patient's experience with the health care encounter, but as an important determinant of health-related outcomes. They argue that patients that had a more positive health care experience may be more likely to comply with treatment or to keep follow-up appointments that are a component of continued care. Patients in 53 hospitals in Minnesota who had either open or laparoscopic elective cholecystectomy were eligible to participate. The ultimate sample of 2,116 had data from two points in time - an initial interview that measured health status prior to surgery, and a questionnaire administered six months after surgery that assessed health status and satisfaction. Satisfaction was measured utilizing an 11-item scale that resulted in the following factors: the quality of the care received, the hospital setting, and time spent with medical staff. Because of the measures used, the researchers could assess both absolute health (how the patients felt after the surgery) and relative health (the degree of improvement in health status from pre to post surgery).

A key result was that "patient satisfaction indeed is related to the outcomes of care, but that the relationship is stronger for absolute outcome than for the relative ones".

This suggests that how a patient is feeling when assessed is more important to patient satisfaction than the degree of improvement in health status over time. The authors conclude by suggesting that this has important implications for organizations that use measures of patient satisfaction as a "report card" since it may reward institutions that have less severely ill patients.

Study design:

\section{Material And Methods}

Cross Sectional Study

\section{Source of data}

An observational cross section study involving adult patients operated as elective basis in department of surgery, Gajra Raja Medical College and J A Group of hospital, Gwalior, during period of 1st February 2015 to 31th January 2016.

\section{Inclusion criteria:}

1. Patients admitted in general surgery ward for elective surgical procedure.

2. Age equal or more than 18 years.

\section{Exclusion criteria:}

1. Age less than 18 years.

2. Patients admitted in general surgery ward for emergency procedure.

3. Patients admitted in general surgery ward who were sick/uncooperative \& therefore cannot take part in study.

\section{Sample Size}

Adult patients operated as elective basis in department of surgery, Gajra Raja Medical College and J A Group of hospital Gwalior, who fulfilled the above inclusion and exclusion criteria were included in the study during the study period of 1st February 2015 to 31th January 2016. About 300 patients were included in study.

\section{Ethical consideration:}

Informed consent was taken from all enrolled patients after detailed counseling. The contents of the consent were read out to the patient in their on language.

\section{Setting:}

The study, approved by ethical committee, was undertaken in the surgery ward at a tertiary level teaching hospital of Gajra Raja Medical College and J A Group of hospital Gwalior. The study period was 1st February 2015 to 31th January 2016. 


\section{Method of collection of data:}

Adult patients operated as elective basis in department of surgery, Gajra Raja Medical College and J A Group of hospital, Gwalior, were provided questionnaire about various aspect of patient satisfaction after randomization.

\section{Statistical analysis}

Observations were categorized and accordingly Chi-Square test or Paired-t tests were used for statistical analysis for comparison. P-value $<0.05$ was considered to be significant $(\mathrm{CI}=95 \%)$. Results were tabulated and represented by suitable graphs and compared with other similar studies.

\section{Observation And Results}

A total of 300 Candidates who fulfilled the inclusion criteria were given questionnaire based on likert scale. Their responses were calculated and analysed statistically using SPSS software, and they revealed the following observations:

1. Age of the patient :Age was grouped into 2 categories $>40$ yrs or $<40 \mathrm{yrs}$.

$<40 \mathrm{yrs}=174$ candidates

$>40 \mathrm{yrs}=126$ candidates

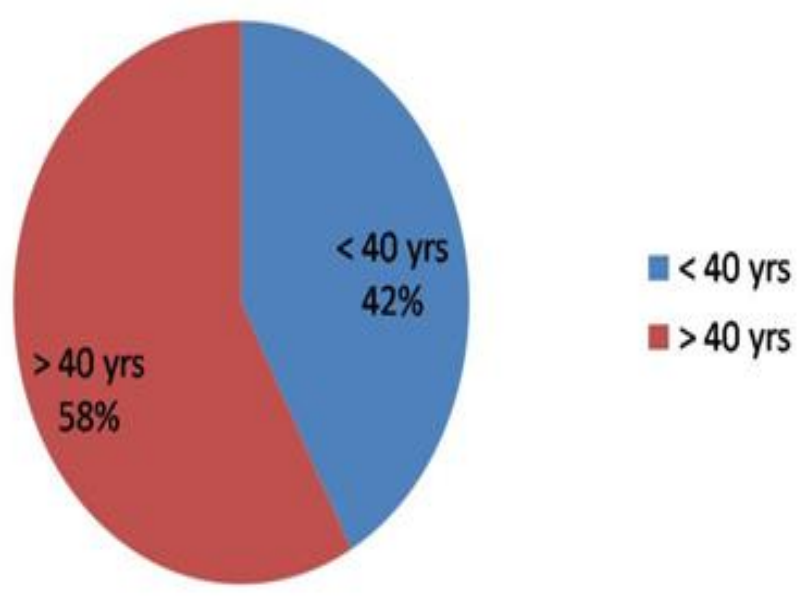

\section{Chart 01: Showing Age distribution of patients}

2. Gender Distribution : Patients' sex was categorized.

Male $=159$

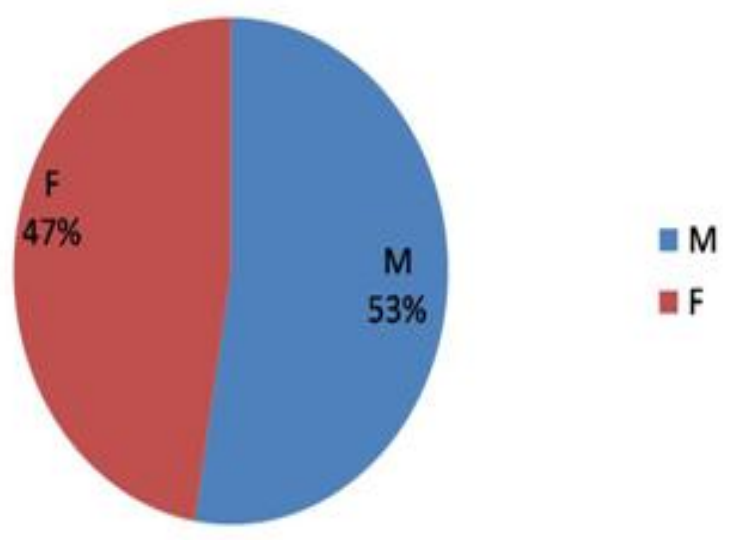

Chart 02: Showing Gender distribution of patients

Female $=141$ 
3. Income groups : Patients' income was categorized as $</=$ Rs $1000=84$ candidates $1000-5000=112$ candidates $5000-10000=60$ candidates $>10000=44$ candidates

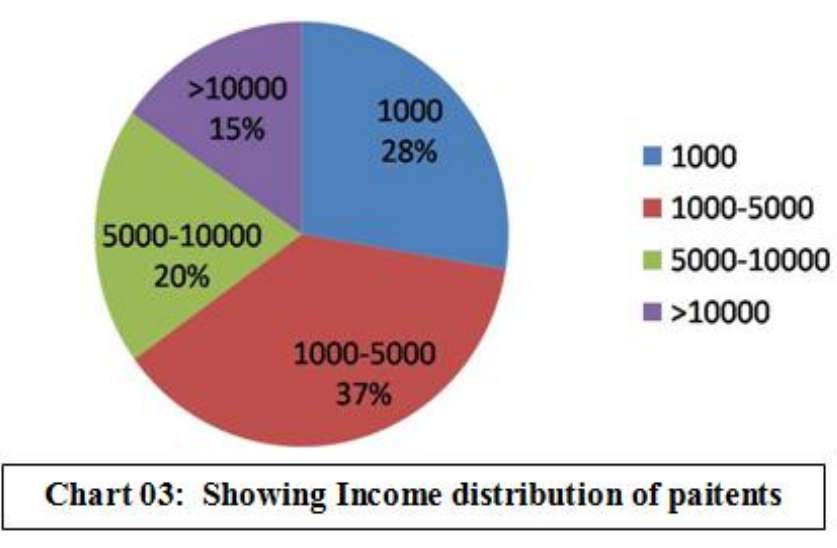

4. Education : All candidates were divided according to their education level Illiterate $=138$ candidates Intermediate $=98$ candidates Graduate $=44$ candidates Postgraduate $=20$ candidates

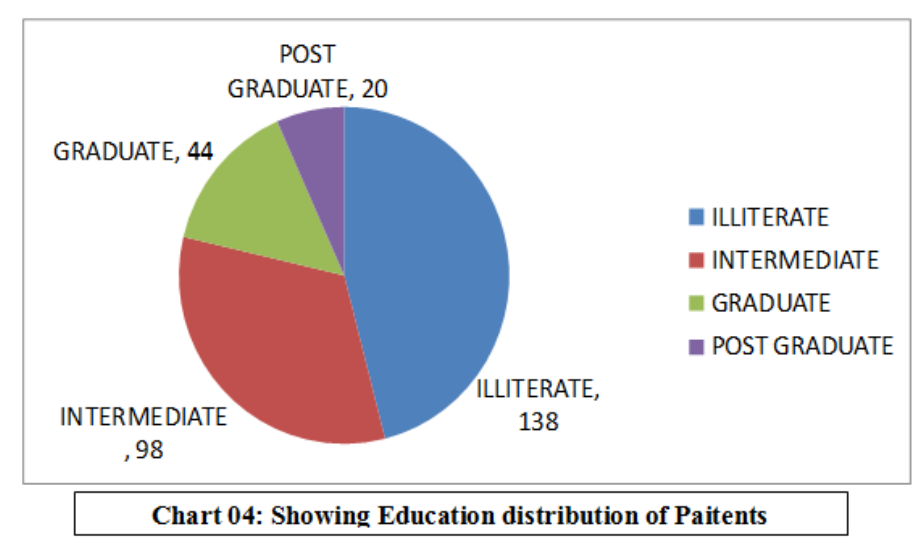

5. Ease of admission procedure :

Dissatisfied $=84 / 300=28 \%$

Satisfied $=84 / 300=28 \%$

Highly satisfied $=132 / 300=44 \%$

Availability of bed :

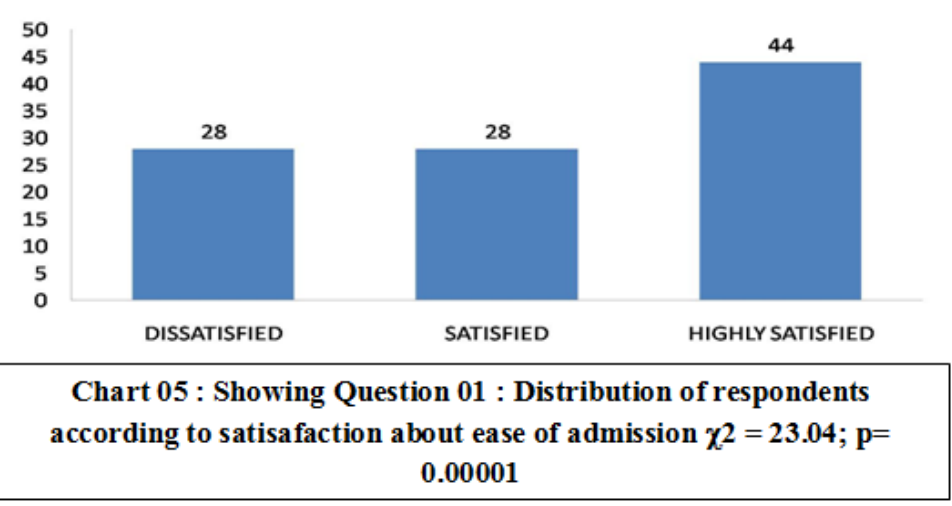


6. Dissatisfied $=147 / 300=49 \%$

Satisfied $=66 / 300=22 \%$

Highly Satisfied $=87 / 300=29 \%$

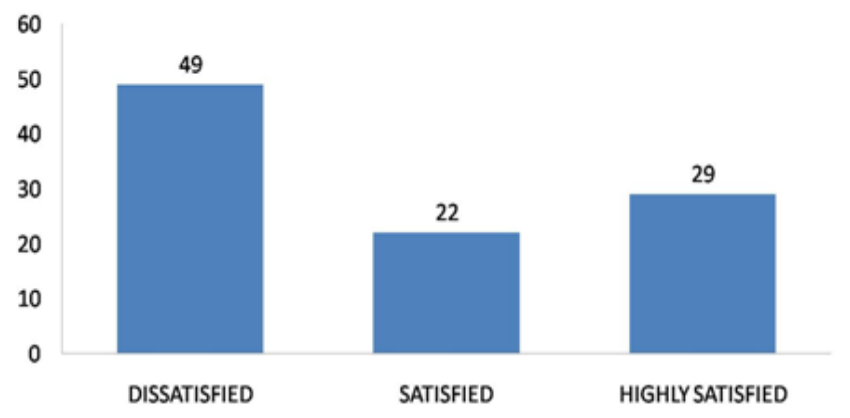

Chart 06- Question 02 : Distribution of respondents according to satisfaction about Availability of beds $\chi 2=53.01 ; p=0.000001$

7. Hygiene of Ward :

Dissatisfied $=174 / 300=58 \%$

Satisfied $=84 / 300=28 \%$

Highly Satisfied $=42 / 300=14 \%$

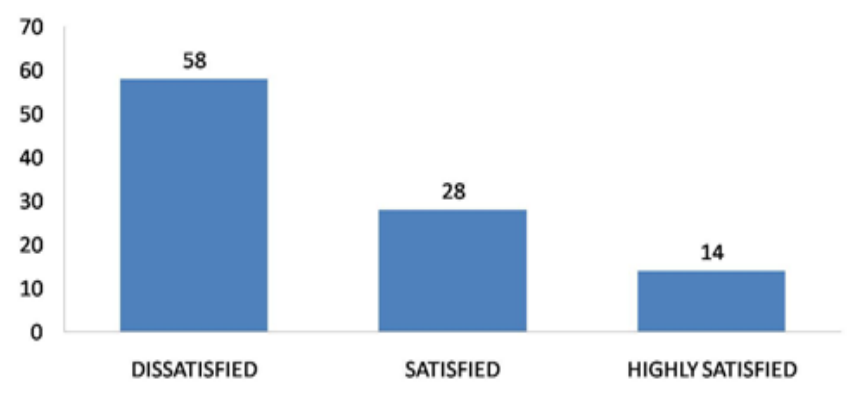

Chart 07 - Questions 03 : Distribution of respondents according to satisfaction about Hygiene of ward $\chi^{2}=136.44 ; p=0.000001$

\section{Quality Of Food :}

Dissatisfied $=126 / 300=42 \%$

Satisfied $=144 / 300=48 \%$

Highly satisfied $=30 / 300=10 \%$

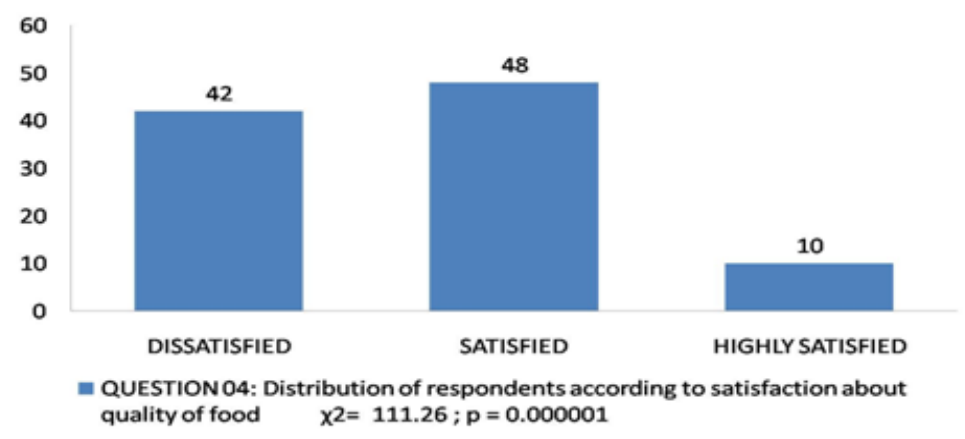

Chart 08 - Question 04: Distribution of respondents according to satisfaction about quality of food $\chi^{2}=111.26 ; p=0.000001$ 
9. Attending Daily Complaints by doctor :

Dissatisfied $=36 / 300=12 \%$

Satisfied $=210 / 300=70 \%$

Highly Satisfied $=54 / 300=18 \%$

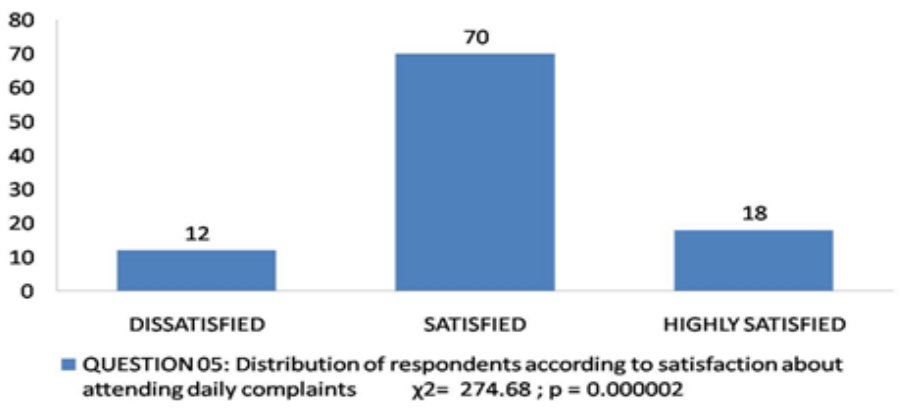

Chart 09 - Question 05: Distribution of respondent according to satisfaction about attending daily complaints $\chi^{2}=274.68$; $\mathrm{p}=\mathbf{0 . 0 0 0 0 0 2}$

10. Attending emergency by doctor :

Dissatisfied $=63 / 300=21 \%$

Satisfied $=141 / 300=47 \%$

Highly satisfied $=96 / 300=32 \%$

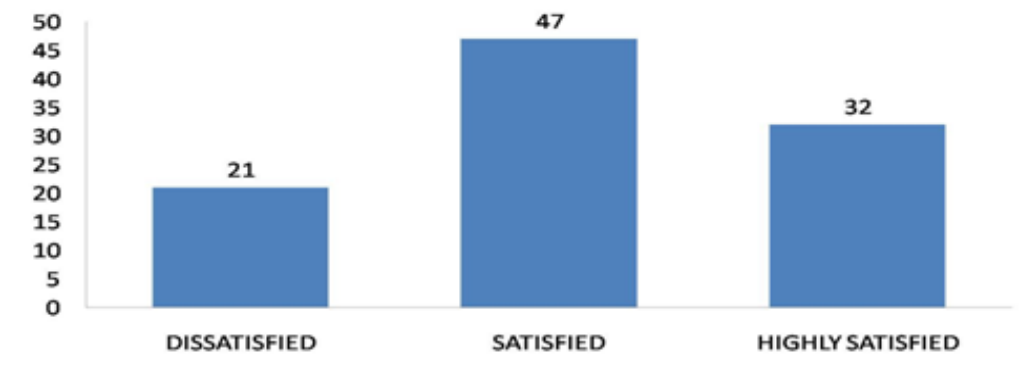

Chart 10 - Question 06: Distribution of respondents according to satisfaction about attending emergency $\chi 2=45.99 ; p=0.000001$

11. Preoperative counseling by doctor :

Dissatisfied $=52 / 300=17.33 \%$

Satisfied $=86 / 300=28.66 \%$

Highly satisfied $=\mathbf{1 6 2} / 300=\mathbf{5 4 . 0 0 \%}$

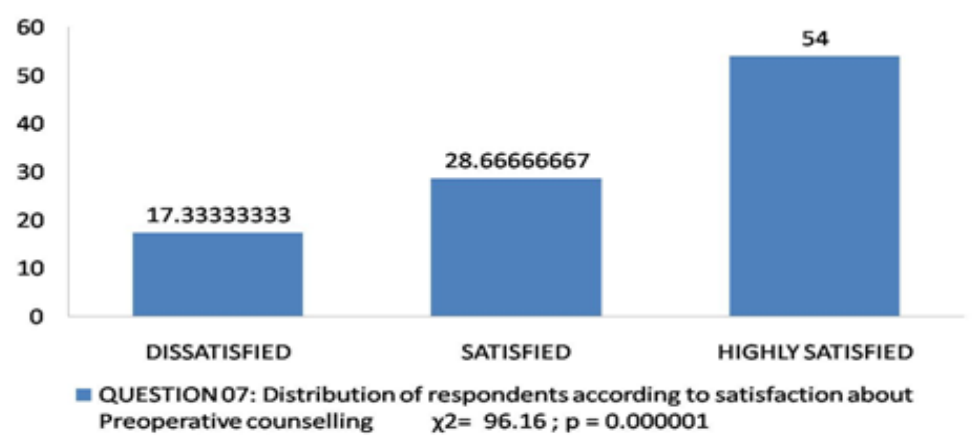

Chart 11- Question 07: Distribution fo respondents according to satisfacton about preoperative counselling $\chi 2=96.15 ; \mathrm{p}=0.000001$ 
12. Preoperative waiting period:

Dissatisfied $=147 / 300=49 \%$

Satisfied $=96 / 300=32 \%$

Highly satisfied $=57 / 300=19 \%$

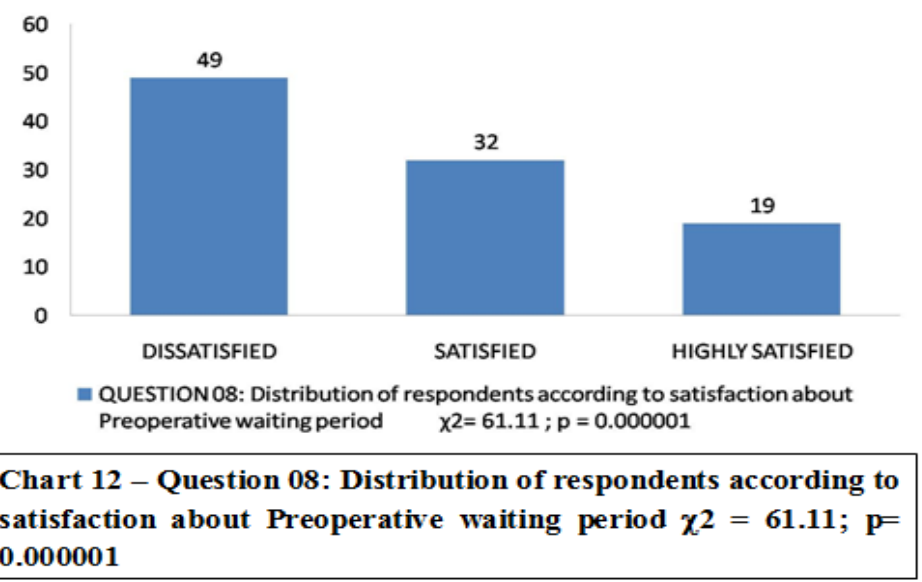

13. Counselling regarding procedure related complications :

Dissatisfied $=84 / 300=28 \%$

Satisfied $=192 / 300=64 \%$

Highly satisfied $=24 / 300=8 \%$

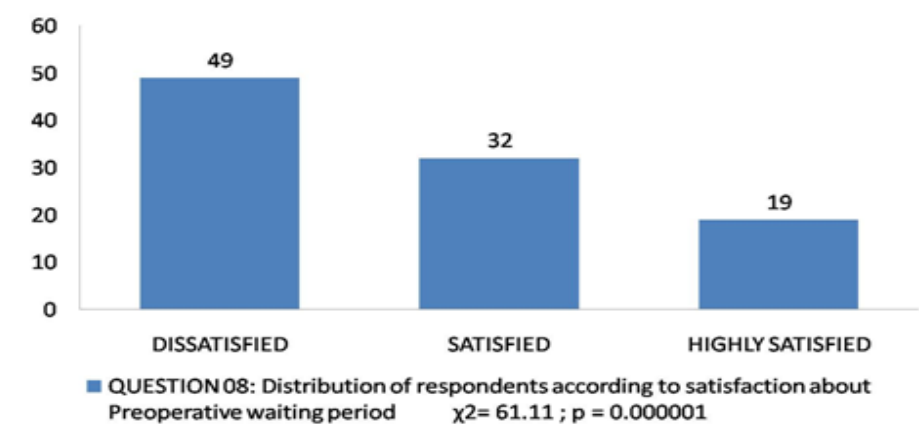

Chart 12 - Question 08: Distribution of respondents according to satisfaction about Preoperative waiting period $\chi^{2}=61.11 ; \mathrm{p}=$ 0.000001

14. Dressing and wound care :

Dissatisfied $=90 / 300=30 \%$

Satisfied $=167 / 300=55.60 \%$

Highly satisfied $=43 / 300=14.33 \%$

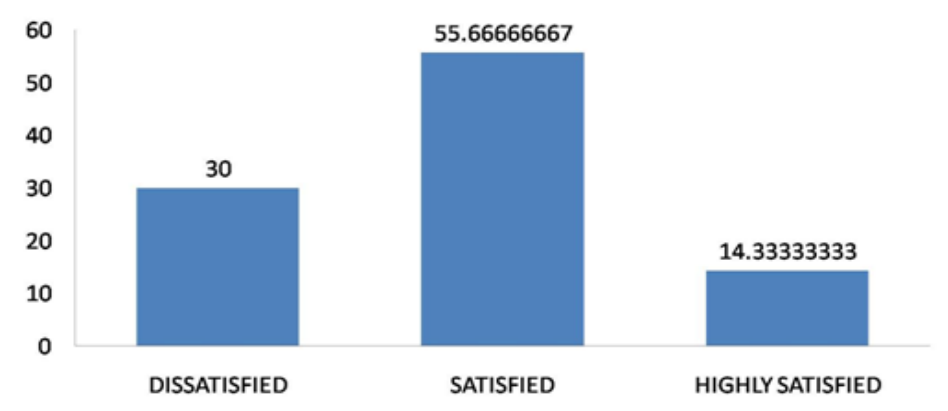

Chart 14-Question 10: Distribution of respondents according to satisfaction about dressing and wound care $\chi^{2}=117.57 ; p=0.000001$ 
15. Behavior of Doctor :

Dissatisfied $=54 / 300=18 \%$

Satisfied $=61 / 300=20.33 \%$

Highly satisfied $=185 / 300=61.66 \%$

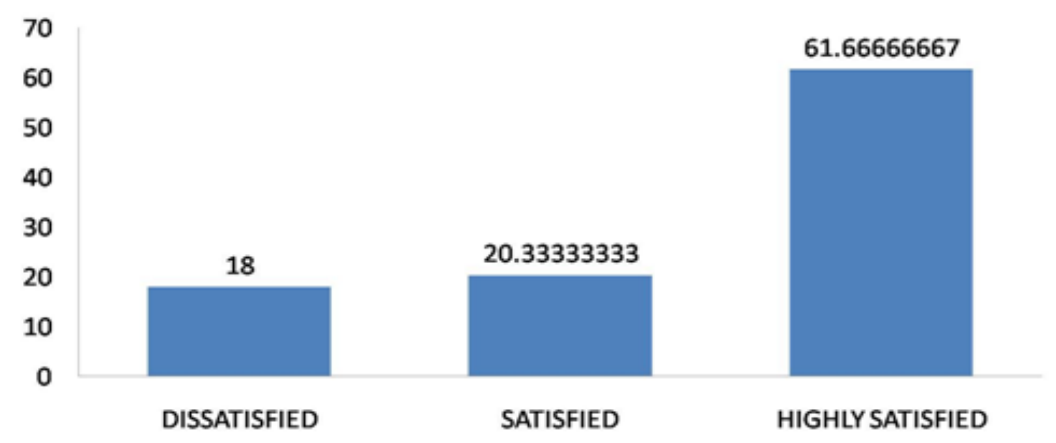

Chart 15 - Question 11: Distribution of respondents according to satisfaction about behaviour of doctor $\chi^{2}=162.93 ; p=0.000001$

16. Behavior of nursing staff :

Dissatisfied $=150 / 300=50 \%$

Satisfied $=87 / 300=29 \%$

Highly satisfied $=63 / 300=21 \%$

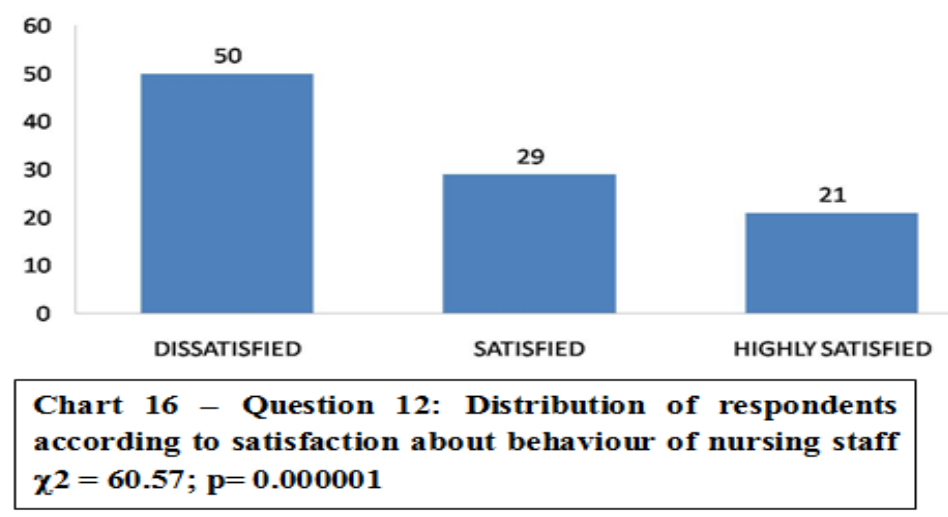

17. Behavior of paramedical staff :

Disssatisfied $=126 / 300=42 \%$

Satisfied $=111 / 300=37 \%$

Highly satisfied $=63 / 300=21 \%$

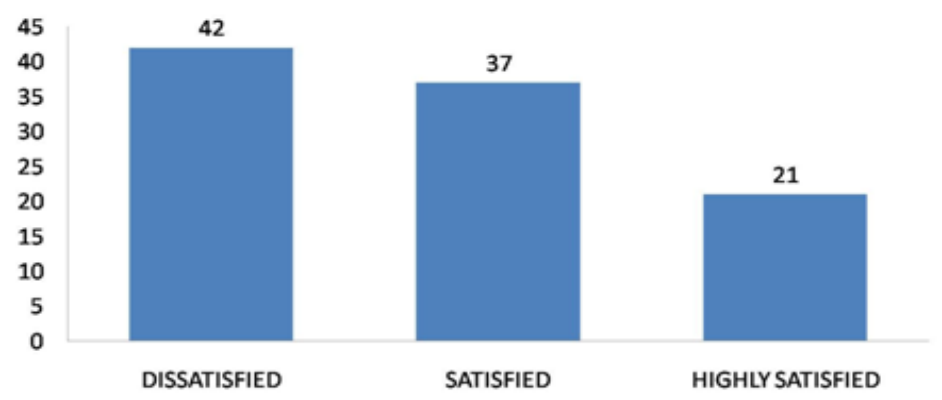

Chart 17 - Question 13: Distribution of respondent according to satisfaction about behaviour of paramedical staff $\chi^{2}=$ 32.49; $p=0.000001$ 
18. Availability of Dressing material and medications in ward :

Dissatisfied $=216 / 300=72 \%$

Satisfied $=54 / 300=18 \%$

Highly satisfied $=30 / 300=10 \%$

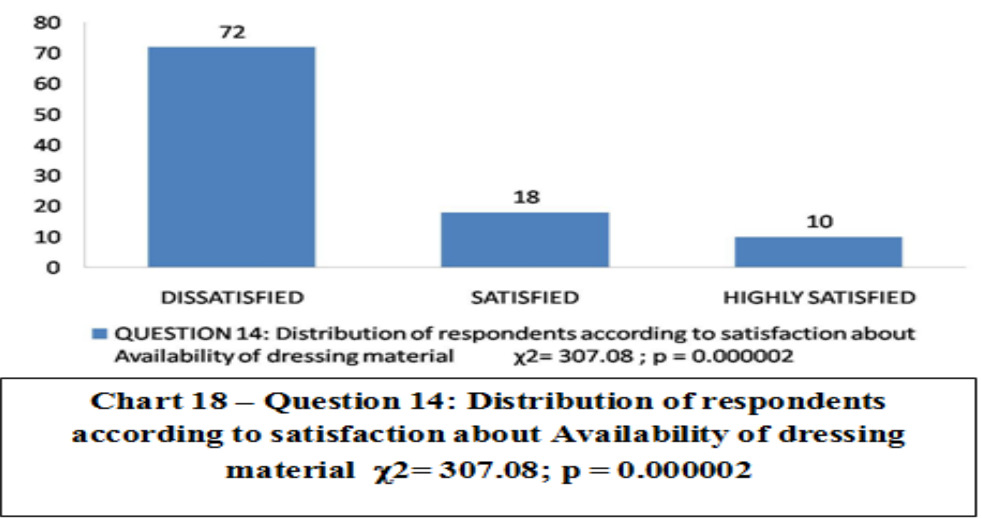

19. Process of discharge after operation :

Dissatisfied $=24 / 300=8 \%$

Satisfied $=30 / 300=10 \%$

Highly satisfied $=246 / 300=82 \%$

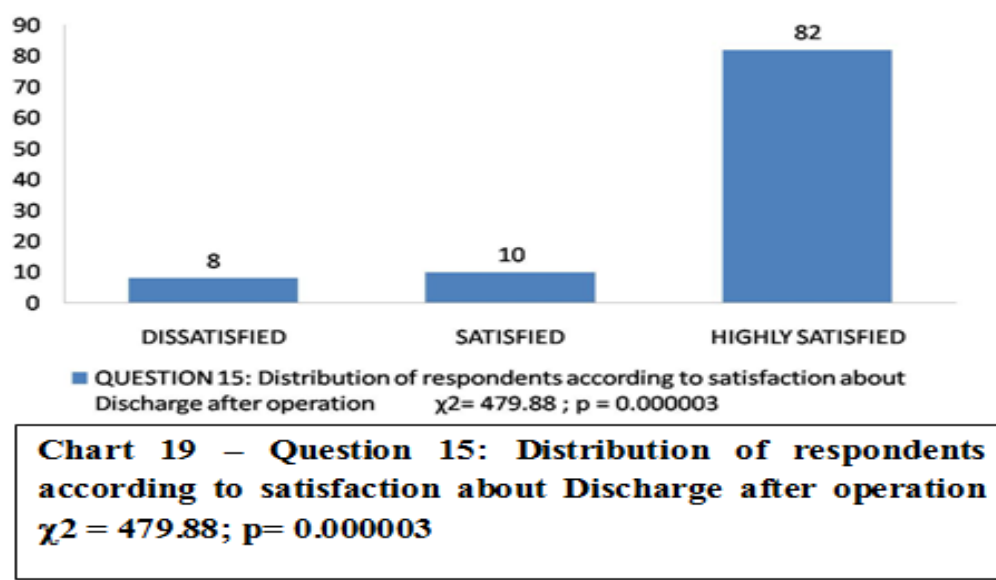

20. Post discharge counseling :

Dissatisfied $=30 / 300=10 \%$

Satisfied $=39 / 300=13 \%$

Highly satisfied $=231 / 300=77 \%$

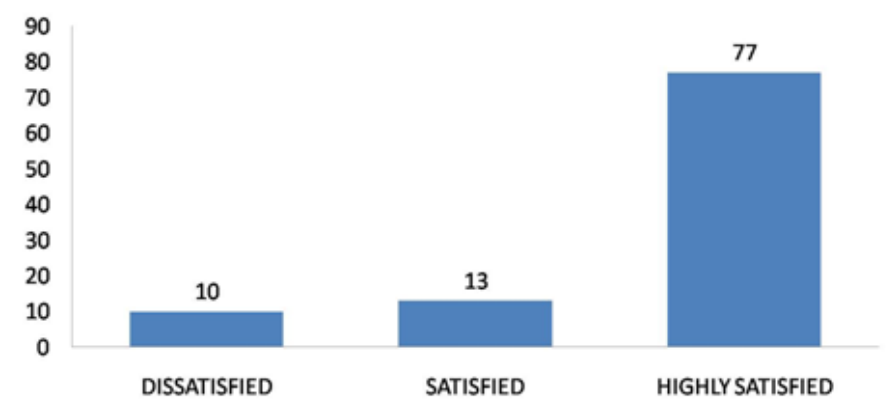

Chart 20 - Question 16: Distribution of responding according to satisfaction about post discharge counselling $\chi^{2}=386.79 ; \mathrm{p}=0.000002$ 
21. Overall satisfaction :

Dissatisfied $=45 / 300=15 \%$

Satisfied $=87 / 300=29 \%$

Highly satisfied $=168 / 300=56 \%$

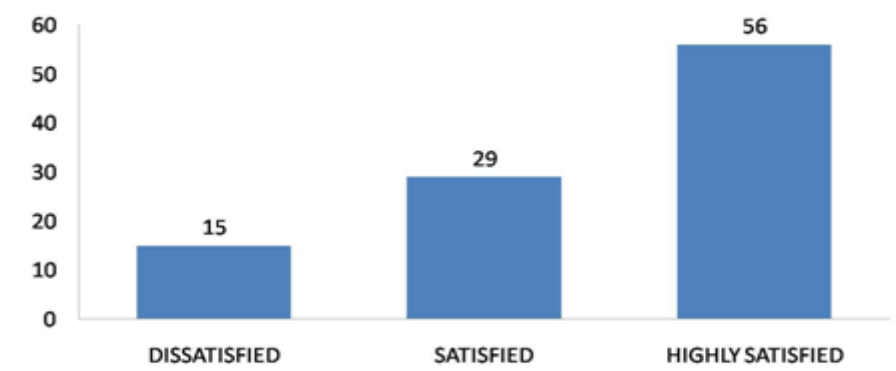

Chart 21 - Question 17: Distribution of responding according to satisfaction about Overal satisfaction $\chi 2=117.27 ; \mathrm{p}=$ 0.000001

A. Analysis of different responses according to age distribution

All the responses were subjected to chi-square analysis. Statistically significant responses are mentioned below:

Attending daily complaints : In <40 yrs age group $11.49 \%$ candidates were dissatisfied with the procedure, $70.10 \%$ were satisfied, and $18.39 \%$ were highly satisfied. Whereas in $>40$ yrs age group $12.69 \%$ were dissatisfied, $69.84 \%$ were satisfied, and $17.46 \%$ were highly satisfied. P-value is 0.04 , which showed statistically significant relation in the above data.

\begin{tabular}{|c|c|c|c|c|}
\hline \multirow{2}{*}{\multicolumn{2}{|c|}{ 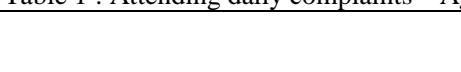 }} & \multicolumn{2}{|l|}{ Age } & \multirow[t]{2}{*}{ Total } \\
\hline & & $>40 \mathrm{yrs}$ & $<40$ yrs & \\
\hline \multirow{3}{*}{$\begin{array}{l}\text { Attending daily } \\
\text { complaints }\end{array}$} & Dissatisfied & $16(12.69)$ & $20(11.49)$ & 36 \\
\hline & Satisfied & $88(69.84)$ & $122(70.1)$ & 210 \\
\hline & Highly satisfied & $22(17.46)$ & $32(18.39)$ & 54 \\
\hline \multicolumn{2}{|l|}{ Total Count } & 126 & 174 & 300 \\
\hline
\end{tabular}

(b) Overall level of satisfaction:

In $<40$ yrs age group $16.66 \%$ candidates were dissatisfied with the procedure, $28.16 \%$ were satisfied, and $55.17 \%$ were highly satisfied. Whereas in $>40$ yrs age group $12.69 \%$ were dissatisfied, $30.15 \%$ were satisfied, and $57.14 \%$ were highly satisfied. P-value is 0.03 , which showed statistically significant relation in the above data.

\begin{tabular}{|l|l|l|l|l|}
\hline \multicolumn{4}{|l|}{ Table 2 :Overall Satisfaction * Age Crosstabulation } \\
\hline \multicolumn{3}{|c|}{ Age } & Total \\
\cline { 3 - 5 } \multicolumn{2}{|c|}{} & $>40$ yrs & 40 yrs & \\
\hline \multirow{3}{*}{ Overall Satisfaction } & Dissatisfied & $16(12.69)$ & $29(16.66)$ & 45 \\
\cline { 2 - 5 } & Satisfied & $38(30.15)$ & $49(28.16)$ & 87 \\
\cline { 2 - 5 } & Highly Satisfied & $72(57.14)$ & $96(55.17)$ & 168 \\
\hline Total Count & 126 & 174 & 300 \\
\hline
\end{tabular}

\section{Analysis of different responses according to gender distribution}

All the responses were subjected to chi-square analysis. Statistically significant responses are mentioned below:

Preoperative Counseling:In Male group $17.61 \%$ candidates were dissatisfied with the procedure, $25.15 \%$ were satisfied, and $57.23 \%$ were highly satisfied. Whereas in female age group $17.02 \%$ were dissatisfied, $32.62 \%$ were satisfied, and $50.35 \%$ were highly satisfied. P-value is 0.03 , which showed statistically significant relation in the above data.

\begin{tabular}{|l|l|l|l|}
\hline \multicolumn{4}{|c|}{ Table 3 :Preoperative counselling * Sex Crosstabulation } \\
\hline \multirow{2}{*}{} & & Sex & Total \\
\cline { 3 - 4 } & Male & Female & \\
\hline
\end{tabular}




\begin{tabular}{|l|l|l|l|l|}
\hline \multirow{2}{*}{$\begin{array}{l}\text { Preoperative } \\
\text { counselling }\end{array}$} & Dissatisfied & $28(17.61)$ & $24(17.02)$ & 52 \\
\cline { 2 - 5 } & Satisfied & $40(25.15)$ & $46(32.62)$ & 86 \\
\cline { 2 - 5 } & Highly Satisfied & $91(57.23)$ & $71(50.35)$ & 162 \\
\hline Total Count & & 159 & 141 & 300 \\
\hline
\end{tabular}

Availability of bed: In Male group $46.54 \%$ candidates were dissatisfied with the procedure, $20.75 \%$ were satisfied, and $32.70 \%$ were highly satisfied. Whereas in female age group $51.77 \%$ were dissatisfied, $23.40 \%$ were satisfied, and $24.82 \%$ were highly satisfied. P-value is 0.041 , which showed statistically significant relation in the above data.

\begin{tabular}{|l|l|l|l|l|}
\hline \multicolumn{5}{|l|}{ Table 4 :Availability of bed * Sex Crosstabulation } \\
\hline \multirow{2}{|c|}{} & Sex & Total \\
\cline { 3 - 5 } \multicolumn{2}{|c|}{} & Male & Female & \\
\hline Availability of bed & Dissatisfied & $74(46.54)$ & $73(51.77)$ & 147 \\
\cline { 2 - 5 } & Satisfied & $33(20.75)$ & $33(23.40)$ & 66 \\
\cline { 2 - 5 } & Highly satisfied & $52(32.70)$ & $35(24.82)$ & 87 \\
\hline Total Count & \multicolumn{1}{|l}{159} & 141 & 300 \\
\hline
\end{tabular}

Overall satisfaction: In Male group $13.20 \%$ candidates were dissatisfied with the procedure, $32.70 \%$ were satisfied, and $54.08 \%$ were highly satisfied. Whereas in female age group $17.02 \%$ were dissatisfied, $24.82 \%$ were satisfied, and $58.15 \%$ were highly satisfied. P-value is 0.021 , which showed statistically significant relation in the above data.

\begin{tabular}{|c|c|c|c|c|}
\hline \multicolumn{5}{|c|}{ Table 5 :Overall Satisfaction * Sex Crosstabulation } \\
\hline & & \multicolumn{2}{|l|}{ Sex } & \multirow{2}{*}{$\begin{array}{l}\text { Tota } \\
1\end{array}$} \\
\hline & & Male & Female & \\
\hline \multirow[t]{3}{*}{ Overall Satisfaction } & Dissatisfied & $21(13.20)$ & $24(17.02)$ & 45 \\
\hline & Satisfied & $52(32.70)$ & $35(24.82)$ & 87 \\
\hline & Highly Satisfied & $86(54.08)$ & $82(58.15)$ & 168 \\
\hline Total Count & & 159 & 141 & 300 \\
\hline
\end{tabular}

Analysis of different responses according to Literacy status:

All the responses were subjected to chi-square analysis. Statistically significant responses are mentioned below:

Availability of bed: In Illiterate group $41.30 \%$ candidates were dissatisfied with the procedure, $22.46 \%$ were satisfied, and $36.23 \%$ were highly satisfied. In Intermediate group $38.77 \%$ were dissatisfied, $31.63 \%$ were satisfied, and $29.59 \%$ were highly satisfied. In Graduate group $81.81 \%$ were dissatisfied, $6.81 \%$ were satisfied, $11.36 \%$ were highly satisfied. In Post-Graduate group $80 \%$ were dissatisfied, $5 \%$ were satisfied, and $15 \%$ were highly satisfied. P-value is 0.044 , which showed statistically significant relation in the above data.

\begin{tabular}{|c|c|c|c|c|c|c|}
\hline & & \multicolumn{4}{|c|}{ Education } & \multirow[t]{2}{*}{ Total } \\
\hline & & Illiterate & Intermediate & Graduate & $\begin{array}{l}\text { Post } \\
\text { Graduate }\end{array}$ & \\
\hline \multirow[t]{3}{*}{$\begin{array}{l}\text { Availability of } \\
\text { bed }\end{array}$} & Dissatisfied & $\begin{array}{l}57 \\
(41.30)\end{array}$ & $\begin{array}{l}38 \\
(38.77)\end{array}$ & $\begin{array}{l}36 \\
(81.81)\end{array}$ & $\begin{array}{l}16 \\
(80)\end{array}$ & 147 \\
\hline & Satisfied & $\begin{array}{l}31 \\
(22.46)\end{array}$ & $\begin{array}{l}31 \\
(31.63) \\
\end{array}$ & $\begin{array}{l}3 \\
(6.81)\end{array}$ & $\begin{array}{l}1 \\
(5)\end{array}$ & 66 \\
\hline & $\begin{array}{l}\text { Highly } \\
\text { Satisfied } \\
\end{array}$ & $\begin{array}{l}50 \\
(36.23) \\
\end{array}$ & $\begin{array}{l}29 \\
(29.59) \\
\end{array}$ & $\begin{array}{l}5 \\
(11.36) \\
\end{array}$ & $\begin{array}{l}3 \\
(15) \\
\end{array}$ & 87 \\
\hline \multicolumn{2}{|l|}{ Total Count } & 138 & 98 & 44 & 20 & 300 \\
\hline
\end{tabular}

Hygiene of ward: In Illiterate group $51.44 \%$ candidates were dissatisfied with the procedure, $34.05 \%$ were satisfied, and $14.49 \%$ were highly satisfied. In Intermediate group $47.95 \%$ were dissatisfied, $36.73 \%$ were satisfied, and $15.30 \%$ were highly satisfied. In Graduate group $88.63 \%$ were dissatisfied, $2.27 \%$ were satisfied, 9.09\% were highly satisfied. In Post-Graduate group $85 \%$ were dissatisfied, and $15 \%$ were highly satisfied. Pvalue is 0.034 , which showed statistically significant relation in the above data. 


\begin{tabular}{|c|c|c|c|c|c|c|}
\hline & & \multicolumn{4}{|c|}{ Education } & \multirow[t]{2}{*}{ Total } \\
\hline & & Illiterate & Intermediat & Graduate & Post Graduate & \\
\hline \multirow[t]{3}{*}{$\begin{array}{l}\text { Hygiene } \\
\text { rd }\end{array}$} & Dissatisfied & $\begin{array}{l}71 \\
(51.44)\end{array}$ & $\begin{array}{l}47 \\
(47.95)\end{array}$ & $\begin{array}{l}39 \\
(88.63)\end{array}$ & $\begin{array}{l}17 \\
(85)\end{array}$ & 174 \\
\hline & Satisfied & $\begin{array}{l}47 \\
(34.05)\end{array}$ & $\begin{array}{l}36 \\
(36.73) \\
\end{array}$ & $\begin{array}{l}1 \\
(2.27)\end{array}$ & $\begin{array}{l}0 \\
(0)\end{array}$ & 84 \\
\hline & Highly satisfied & $\begin{array}{l}20 \\
(14.49)\end{array}$ & $\begin{array}{l}15 \\
(15.30)\end{array}$ & $\begin{array}{l}4 \\
(9.09)\end{array}$ & $\begin{array}{l}3 \\
(15)\end{array}$ & 42 \\
\hline Total & & 138 & 98 & 44 & 20 & 300 \\
\hline
\end{tabular}

Preoperative waiting period: In Illiterate group $48.55 \%$ candidates were dissatisfied with the procedure, $36.95 \%$ were satisfied, and $18.84 \%$ were highly satisfied. In Intermediate group $41.83 \%$ were dissatisfied, $37.75 \%$ were satisfied, and $20.40 \%$ were highly satisfied. In Graduate group $70.45 \%$ were dissatisfied, $11.36 \%$ were satisfied, $18.18 \%$ were highly satisfied. In Post-Graduate group $70 \%$ were dissatisfied, $15 \%$ were satisfied and $15 \%$ were highly satisfied. P-value is 0.045 , which showed statistically significant relation in the above data.

\begin{tabular}{|c|c|c|c|c|c|c|}
\hline & & \multicolumn{4}{|c|}{ Education } & \multirow[t]{2}{*}{ Total } \\
\hline & & Illiterate & Intermediate & Graduate & Post Graduate & \\
\hline \multirow[t]{3}{*}{$\begin{array}{l}\text { Preoperative waiting } \\
\text { period }\end{array}$} & Dissatisfied & $\begin{array}{l}61 \\
(48.55)\end{array}$ & $\begin{array}{l}41 \\
(41.83)\end{array}$ & $\begin{array}{l}31 \\
(70.45) \\
\end{array}$ & $\begin{array}{l}14 \\
(70)\end{array}$ & 147 \\
\hline & Satisfied & $\begin{array}{l}51 \\
(36.95) \\
\end{array}$ & $\begin{array}{l}37 \\
(37.75) \\
\end{array}$ & $\begin{array}{l}5 \\
(11.36) \\
\end{array}$ & $3(15)$ & 96 \\
\hline & $\begin{array}{l}\text { Highly } \\
\text { satisfied }\end{array}$ & $\begin{array}{l}26 \\
(18.84)\end{array}$ & $\begin{array}{l}20 \\
(20.40)\end{array}$ & $\begin{array}{l}8 \\
(18.18)\end{array}$ & $3(15)$ & 57 \\
\hline \multicolumn{2}{|l|}{ Total Count } & 138 & 98 & 44 & 20 & 300 \\
\hline
\end{tabular}

\section{Analysis of different responses based on economic groups:}

Hygiene of ward: In $<1000$ income group $58.33 \%$ candidates were dissatisfied with the procedure, $26.19 \%$ were satisfied, and $15.47 \%$ were highly satisfied. In $1000-5000$ income group $47.32 \%$ were dissatisfied, $35.71 \%$ were satisfied, and $16.96 \%$ were highly satisfied. In 5000-10000 income group 60\% were dissatisfied, $31.66 \%$ were satisfied, $8.33 \%$ were highly satisfied.

In $>10000$ income group $81.81 \%$ were dissatisfied, $6.81 \%$ were satisfied and $11.36 \%$ were highly satisfied. P-value is 0.036 , which showed statistically significant relation in the above data.

\begin{tabular}{|c|c|c|c|c|c|c|}
\hline \multicolumn{7}{|c|}{ Table 9 :Hygiene of ward * Income Crosstabulation } \\
\hline & & \multicolumn{4}{|l|}{ Income } & \multirow[t]{2}{*}{ Total } \\
\hline & & $</=1000$ & $1000-5000$ & $5000-10000$ & $>10000$ & \\
\hline \multirow[t]{3}{*}{ Hygiene of ward } & Dissatisfied & $\begin{array}{l}49 \\
(58.33) \\
\end{array}$ & $\begin{array}{l}53 \\
(47.32) \\
\end{array}$ & $\begin{array}{l}66 \\
(60) \\
\end{array}$ & $\begin{array}{l}36 \\
(81.81) \\
\end{array}$ & 174 \\
\hline & Satisfied & $\begin{array}{l}22 \\
(26.19) \\
\end{array}$ & $\begin{array}{l}40 \\
(35.71)\end{array}$ & $\begin{array}{l}19 \\
(31.66)\end{array}$ & $\begin{array}{l}3 \\
(6.81) \\
\end{array}$ & 84 \\
\hline & $\begin{array}{l}\text { Highly } \\
\text { satisfied }\end{array}$ & $\begin{array}{l}13 \\
(15.47)\end{array}$ & $19(16.96)$ & $\begin{array}{l}5 \\
(8.33) \\
\end{array}$ & $\begin{array}{l}5 \\
(11.36)\end{array}$ & 42 \\
\hline \multicolumn{2}{|l|}{ Total Count } & 84 & 112 & 60 & 44 & 300 \\
\hline
\end{tabular}

Quality of food: In $<1000$ income group $41.66 \%$ candidates were dissatisfied with the procedure, $48.80 \%$ were satisfied, and $9.52 \%$ were highly satisfied. In $1000-5000$ income group $52.67 \%$ were dissatisfied, $36.60 \%$ were satisfied, and $10.71 \%$ were highly satisfied.

In 5000-10000 income group $40 \%$ were dissatisfied, $50 \%$ were satisfied, $10 \%$ were highly satisfied. In $>10000$ income group $18.18 \%$ were dissatisfied, $72.72 \%$ were satisfied and $9.09 \%$ were highly satisfied. P-value is 0.04 , which showed statistically significant relation in the above data. 


\begin{tabular}{|c|c|c|c|c|c|c|}
\hline & & \multicolumn{4}{|l|}{ Income } & \multirow[t]{2}{*}{ Total } \\
\hline & & $</=1000$ & $1000-5000$ & $5000-10000$ & $>10000$ & \\
\hline \multirow[t]{3}{*}{$\begin{array}{l}\text { Quality of } \\
\text { food }\end{array}$} & Dissatisfied & $\begin{array}{l}35 \\
(41.66) \\
\end{array}$ & $\begin{array}{l}59 \\
(52.67) \\
\end{array}$ & $\begin{array}{l}24 \\
(40)\end{array}$ & $\begin{array}{l}8 \\
(18.18) \\
\end{array}$ & 126 \\
\hline & Satisfied & $\begin{array}{l}41 \\
(48.80)\end{array}$ & $\begin{array}{l}41 \\
(36.60)\end{array}$ & $\begin{array}{l}30 \\
(50)\end{array}$ & $\begin{array}{l}32 \\
(72.72)\end{array}$ & 144 \\
\hline & Highly satisfied & $\begin{array}{l}8 \\
(9.52) \\
\end{array}$ & $\begin{array}{l}12 \\
(10.71)\end{array}$ & $\begin{array}{l}6 \\
(10)\end{array}$ & $\begin{array}{l}4 \\
(9.09)\end{array}$ & 30 \\
\hline \multicolumn{2}{|c|}{ Total Count } & 84 & 112 & 60 & 44 & 300 \\
\hline
\end{tabular}

Overall satisfaction: In $<1000$ income group $08.33 \%$ candidates were dissatisfied with the procedure, $34.52 \%$ were satisfied, and $57.14 \%$ were highly satisfied. In 1000-5000 income group $16.96 \%$ were dissatisfied, $37.5 \%$ were satisfied, and $45.53 \%$ were highly satisfied. In 5000-10000 income group $28.33 \%$ were dissatisfied, $16.66 \%$ were satisfied, $55 \%$ were highly satisfied. In $>10000$ income group $04.54 \%$ were dissatisfied, $30.63 \%$ were satisfied and $81.81 \%$ were highly satisfied. P-value is 0.036 , which showed statistically significant relation in the above data.

\begin{tabular}{|c|c|c|c|c|c|c|}
\hline \multicolumn{7}{|c|}{ Table 11 :Overall Satisfaction * Income Crosstabulation } \\
\hline & & \multicolumn{4}{|l|}{ Income } & \multirow[t]{2}{*}{ Total } \\
\hline & & $</=1000$ & $\begin{array}{l}1000- \\
5000\end{array}$ & $5000-10000$ & $>10000$ & \\
\hline \multirow[t]{3}{*}{$\begin{array}{l}\text { Overall } \\
\text { Satisfaction }\end{array}$} & Dissatisfied & $\begin{array}{l}7 \\
(8.33)\end{array}$ & $\begin{array}{l}19 \\
(16.96)\end{array}$ & $\begin{array}{l}17 \\
(28.33)\end{array}$ & $\begin{array}{l}2 \\
(4.54)\end{array}$ & 45 \\
\hline & Satisfied & $\begin{array}{l}29 \\
(34.52)\end{array}$ & $\begin{array}{l}42 \\
(37.5)\end{array}$ & $\begin{array}{l}10 \\
(16.66)\end{array}$ & $\begin{array}{l}6 \\
(30.63)\end{array}$ & 87 \\
\hline & Highly Satisfied & $\begin{array}{l}48 \\
(57.14)\end{array}$ & $\begin{array}{l}51 \\
(45.53)\end{array}$ & $\begin{array}{l}33 \\
(55)\end{array}$ & $\begin{array}{l}36 \\
(81.81)\end{array}$ & 168 \\
\hline \multicolumn{2}{|l|}{ Total Count } & 84 & 112 & 60 & 44 & 300 \\
\hline
\end{tabular}

\section{Discussion}

Patient satisfaction is a critical health care outcome indicator and should be given focus by the hospital administrators. As a tertiary level hospital \& teaching institute who serve populations of Gwalior \& nearby areas of Morena, Bhind, Datia, Sheopur, Shivpuri, Jhansi etc patient satisfaction is one of the important indicators as quality control for health services provided. in our study we tried to highlight the areas of dissatisfaction amongst patients operated as elective basis in department of general surgery J.A. Group of Hospital. Health care sector is ever evolving, and progressive which constantly requires reassessment. Our study is an attempt to compare patients from different socioeconomic backgrounds and evaluate their level of satisfaction for different services being provided to admitted patients.

In our study 300 patients operated as elective basis in department of general surgery and J.A. Group of Hospital in between $1^{\text {st }}$ february 2015 to $31^{\text {st }}$ january 2016 were included after fulfillment of our inclusion criteria.

We devided the patients on basis of age, sex, educational qualifications and income groups.we circulated a questionnaire including 17 questions about patient satisfaction and survey was done. Data collected, compiled and analysed with help of spss software.

Distribution of demographic variables-

Age - In our study there were more candidates that belong to age group of less than or equal to 40 years. Those having age less than or equal to 40 years were 174 candidates. Those having age more than 40 years were 126 candidates.

Sex - In our study there were more male members participating in our study. Total number of Males was 159; total number of Females was 141.

Income - In our study there were maximum frequency in those having monthly income of Rs1000Rs5000/month. Candidates who were having Income </= Rs1000/month were 84, Rs1000-Rs5000 were 112, Rs5000-10000 were 60, and those having >Rs 10000 were 44.

Education - In our study there were maximum of those belonging to illiterate group 138 candidates, 98 candidates belonged to up to Intermediate level, 44 candidates belonged to up to graduate groups, 20 candidates belonged to postgraduate level. 
Comparison of level of satisfaction for individual responses Ease of admission procedure More number of people were highly satisfied (44\%).

Availability of bed More number of people were dissatisfied $=49 \%$ in which statistically significant number of females $(51.77 \%)$ had more percentage of dissatisfaction than males $(46.54 \%)$, also higher literacy was statistically more associated with dissatisfaction.

Hygiene of ward More number of people were dissatisfied (58\%), Statistically significant number of higher literacy rate group were shown having dissatisfaction (88.63\%). Also >Rs 10000/month income group have more dissatisfaction $(81.81 \%)$ than lower groups.

Quality of food: Almost equal number of candidates are satisfied and dissatisfied.

Attending daily complaints by doctor: Majority people are satisfied(70\%), especially more number of younger age group were more satisfied $(88.51 \%)$ than old age $(87.31 \%)$

Attending emergency by doctor: Majority were satisfied.

Preoperative counseling by doctor: Majority of the people were highly satisfied(54\%), overall males were less satisfied than females.

Preoperative waiting period: More number of people were dissatisfied(49\%). More literacy level had statistically significant relation to percentage of people having dissatisfaction.

Counselling regarding procedure related complications: Majority were satisfied (64\%)

Dressing and wound care: Majority were satisfied(55.60\%)

Behavior of doctor: Majority of people were highly satisfied(61.66\%)

Behavior of nursing staff: Majority were dissatisfied(50\%)

Behavior of paramedical staff: More number of people ere dissatisfied.

Availability of Dressing material and medications in ward: Majority were dissatisfied(72\%)

Process of discharge after operation: Majority were highly satisfied(82\%)

Post discharge counseling: Majority were highly satisfied (77\%)

Overall satisfaction: Majority were highly satisfied (56\%). Younger age group had more dissatisfaction $(16.66 \%)$ than old age group (12.69\%). Females were overall more satisfied $(17.02 \%)$ in comparison to males $(13.20 \%)$. Percentage of satisfaction was significantly less in higher income groups.

Previously a lot of work about patient satisfaction is done in western countries but in india there is a lot of areas about patient satisfaction are untouched.

We compared our study with various previous studies which were conducted in different cities and countries and observed following significant co-relations.

A study done at Taipei Medical University, School of health care administration "Patient satisfaction with inpatient services at National Referral Hospital of Belize, Central America" ${ }^{,[36]}$ from June 2012 to December 2012.

In above mentioned study they were having different criteria for patient satisfaction as privacy, participation in decision making, homely environment of hospitals, cleanliness of bed sheets, aroma of ward, cooperation of staff and doctors in healing process, ease of availability of services, communication skill of laboratory staff and attitude of paramedical staff.

Whereas we are till now asking about availability of beds and medicines which shows clear difference between both scenarios. It is not surprising as in India patient to bed ratio is still 0.6 beds/1000 people on01/07/2016 as reported by WHO. In India every government allopathic doctor serves a population about 11000.This might be a result of population explosion and uneven distribution of health care facilities.

A study done in Narayan Medical College, Nellore (Andhra Pradesh) "A study on the satisfaction of patients with reference of hospital services" ${ }^{\text {"[3] }}$ from May 2011 to July 2011.

In above mentioned study they found that male patients were more satisfied then female patients but in our study female patients are found more satisfied.

A study done in Juaben Government Hospital Ghana "An assessment of consumer care and satisfaction in government health care institution in Ghana" ${ }^{[38]}$ from June 2010 to April 2011.

In above mentioned study they found significant increase in revenue after accepting recommendations of their study during study duration.

A study done in Madina Teaching Hospital University, Faisalabad, Pakistan "Study of patient satisfaction and hospital care in Pakistan". ${ }^{[39]}$ from July 2011 to November 2011.

Above mentioned study also revealed that patients with higher literacy rate and higher income group were less satisfied in compare to patients with lower literacy rate and lower income group.

\section{Conclusion}

Patient satisfaction is fundamentally a subjective judgment that results from the appraisal of health care experience and involving the explicit and implicit comparison of the actual events with the expectation of the 
individuals. It is a complex interaction between the psychosocioeconomic aspects of each individual and the morbidity level of the patient, which need to be further investigated.

In our study we observed that females are overall more satisfied than males which shows less expectations of female patients towards healthcare delivery system in this male dominating society.we also found more expectations in patients with higher education and higher income groups so they were less satisfied towards present healthcare system.

This study will facilitate more consumer based approach of the health care system and improve the compliance and efficacy of health care delivery. It should come in our basic practice to give preference about patient satisfaction and to include patient in decision regarding their treatment and policy making.

More studies should be done in this field and administrative authority should try to implement the recommendation towards patient satisfaction.

\section{Summary}

This observational cross section study involved 300 adult patients operated as elective basis in department of surgery, Gajra Raja Medical College and J A Group of hospital, Gwalior, during period of 1st February 2015 to 31th January 2016.

\section{Following results were obtained in our study:-}

1) $44 \%$ Patients were highly satisfied with regard to ease of admission.( $p$ value $=0.00001)$

2) $49 \%$ Patients were dissatisfied with regard to availability of beds in wards. $(p$ value $=0.000001$ )

3) $58 \%$ Patients were dissatisfied with hygine and cleaniness of wards. $(p$ value $=0.00001)$

4) $48 \%$ Patients were satisfied with quality of food in ward. $(\mathrm{p}$ value $=0.000001)$

5) $70 \%$ Patients were satisfied with doctors for attending their daily complaints. $(p$ value $=0.00002)$

6) $47 \%$ Patients were satisfied with regard to availability of doctors at the time of emergencies.(p value $=0.00001$ )

7) $54 \%$ Patients were highly satisfied with pre operative counseling. $(\mathrm{p}$ value $=0.00001)$

8) $49 \%$ Patients were dissatisfied with waiting period before operation. $(\mathrm{p}$ value $=0.00001)$

9) $64 \%$ Patients were satisfied with counseling regarding complications of operation. ( $p$ value-0.00002)

10) $56 \%$ Patients were satisfied with post operative dressing and wound care. $(p$ value $=0.00001)$

11) $61 \%$ Patients were highly satisfied with behavior of doctors in ward. $(p$ value $=0.00001)$

12) $50 \%$ Patients were dissatisfied with behavior of nursing staff in ward. $(p$ value $=0.000001)$

13) $42 \%$ Patients were dissatisfied with behavior of paramedical staff in ward. $(p$ value $=0.00001)$

14) $72 \%$ Patients were dissatisfied with availability of medicines and dressing material in ward.(p value $=0.00002$ )

15) $82 \%$ Patients were highly satisfied with discharge procedures. $(p$ value $=0.00003)$

16) $77 \%$ Patients were highly satisfied with post discharge councelling.(p value $=0.00002)$

17) $56 \%$ Patients were highly satisfied overall during hospital stay.(p value $=0.0001)$

18) With regard to age groups $>40$ yrs. patients were more satisfied towards attending daily complaints by doctors but overall satisfaction was more in age group $<40 \mathrm{yrs}$.

19) With regard to gender distribution females were more satisfied with pre-operative counseling but more dissatisfied with availability of beds and females were more satisfied in terms of overall satisfaction.

20) With regard to level of education, as level of education increases, satisfaction towards availability of beds in ward,hygine of ward and pre-operative waiting period decreases.

21) With regard to level of income, as level of income increases, satisfaction towards hygine and quality of food decreases.

22) Overall patients with lower education level and lower income groups were more satisfied.

\section{Recommendations}

After our study we would like to recommend some areas which have a space for improvement and might be useful for Jay Arogya Hospital and Groups administration to improve patient satisfaction:-

1) Availability of beds in wards should be increased specially in Kamla Raja Hospital.

2) Cleanliness and hygiene in wards should be improved especially of toilets and dressing rooms.

3) Elective surgical patients should be admitted only after Pre Anesthetic Checkup fitness to avoid unnecessary delay in surgery.

4) Number of nursing staff should be increased.

5) Junior doctors, nurses and paramedical staff should be counseled about patient satisfaction and communication.

6) Availability and more importantly accessibility of medicines and dressing materials to patients should be ensured. 


\section{Bibliography}

[1]. Huber M,Knttnerus JA, Green,L.,Vander Host:Constitution of the World Health Organization. World Health Organization: Basic documents.British Medical Journal 2011; 45:1136.

[2]. Saleh MA, Hattan A, Hassan A, Basem SE and Ahmed AK : Determinants of Patient Satisfaction in the Surgical ward at a University Hospital in Saudi Arabia. Life Science Journal 2012; 9(1):277-280.

[3]. Delbanco TL: Quality of care through the patients' eyes. British Medical Journal 1996; 313: 832-833.

[4]. Bruster S, Jarman B, Bosanquet N, Weston D, Erens R, Delbanco TL:National survey of hospital patients. British Medical Journal 1994, 309: 1542-1546.

[5]. Delbanco TL: Enriching the doctor-patient relation: inviting the patient's perspective. Ann Intern Med 1992; 116: 414-418.

[6]. Wensing M, Elwyn G: Methods for incorporating patients' views in health care. British Medical Journal 2003; 326:877-879.

[7]. Agarwal A, Garg S, Pareek U: A Study Assessing Patient Satisfaction in a Tertiary Care Hospital in India: The Changing Healthcare Scenario. Journal of Communicable Disease 2009; 41(2):109-112.

[8]. Kotler P, Keller KL: Marketing management. New Jersey:Pearson Education Inc, Upper Saddle River2007;21(3):789.

[9]. Hall MA, Bitner MJ, Gremler DD: Irish society for quality and safety in health care. Measurement of patient satisfaction guidelines: Health Strategy Implementation Project.International Journal of Service Industry Management2003; 10: 4-25.

[10]. Shemwell DJ, Yavas U, Bilgin Z: Customer service provider relationships: an empirical test of service quality, satisfaction and relationship-oriented outcomes. International Journal of Service Industry Management2009; 20 (2):155-168.

[11]. Johansson P, Oleni M, Fridlund B: Patient satisfaction with nursing care in the context of health care: a literature study. Scandinavian Journal of Caring Science2007; 16 (4):337-344.

[12]. Thom DH, Hall MA, Pawlson LG: Measuring patients trust in physician when assessing quality of care. Health Affair1997; 23(4):124-132.

[13]. Brenan PF: Patient Satisfaction and Normative decision Theory. Journal of the American Medical Informatics Association2004; 2 (4): 250-259.

[14]. Linder-Pelz: Toward a theory of patient satisfaction. Journal Of Social Science And Medicine2006; 16:577-581.

[15]. Solomon MR: Consumer behavior, Buying, Having and Being. Pearson Education, inc 2009; 8(2): 413.

[16]. Zeithaml VA, Bitner MJ, Gremler DD: International Journal of Service Industry Management McGraw-Hill 2006;4: 66

[17]. Laroche M, Kalamas M, Cheikhrouhou S, Cezard A: An Assessment of the Dimensionality of Should and Will Service Expectations. Canadian Journal of Administrative Sciences-Revue Canadienne Des Sciences De L Administration2008; 21 (4): 361 375.

[18]. Haywood-Farmer J: A Conceptual Model of $\quad$ Service Quality, Journal of Operations \& Production Management1998; 8(6): 9-29.

[19]. Parasuraman A, Zeithaml VA, Berry LL: A conceptual model of service quality and its implications for future research, Journal of Marketing2009; 49: 41-50.

[20]. Laroche M, Kalamas M, Cheikhrouhou S, Cezard A: Canadian Journal Of Administrative Sciences-Revue Canadienne Des Sciences De L Administration2002; 21(4): 361-375.

[21]. Kotler P, Keller KL:The determinants of perceived servicen quality and its relationship with satisfaction. Journal of Service Marketing2007; 14(3): 217-231.

[22]. Jones AJI: On the concept of trust: Decision Support Systems.Elsevier Science B.V.2002; 33(3): $225-232$.

[23]. Giffin K: The contribution of studies of source credibility to a theory of interpersonal trust in the communication process. Psychological Bulletin1996, 68 (2), 104- 120.

[24]. Mechanic D, Meyer D: Concept of trust among patients with serious illness. Journal of Social Science and Medicine2001; 51:657668 .

[25]. Thom DH, Hall MA, Pawlson LG: Measuring patients trust in physician when assessing quality of care. Health Affairs1996; 23 (4):124-132.

[26]. Davies HTO, Rundall TG: Managing patient trust in managed care. The Milbank Quarterly2001;78 (4):609-622.

[27]. Balkrishnan R, Dugan E, Fabian T, Camacho M.A. Trust and satisfaction with physicians, insurers and medical profession. Journal of Medical Care1998; 41 (9):1058-1064.

[28]. Herbig P, Milewicz J: The relationship of reputation and credibility to brand success. Journal of Consumer Marketing1975; 10(3):18-24.

[29]. Bromley D: Comparing Corporate Reputations: League Tables, Quotients, Benchmarks, or Case Studies? Corporate Reputation Review, London1996; 5(1): 35-60.

[30]. Hibbard JH, Stockard J, Tusler M: Hospital performance reports: Impact on quality, market share and reputation. Health Affairs 2007; 24 (4): 1150-1160.

[31]. Bourke R: An investigation into the reputation of a public hospital. Thesis work submitted to the Waterford Institute of Technology 2009; 5(2):39-40.

[32]. Satir C: The nature of corporate reputation and the measurement of reputation components: An empirical study within a hospital. Corporate Communications: An International Journal2014; 11(1): 56-63.

[33]. Power JD: Reputation plays a vital role in influencing a patients' choice of hospitals. Press Release; Mc-Graw Hill Financial2005; 7:138-170.

[34]. Fox C: A national customer satisfaction barometer: The Swedish experience. Journal of marketing2004; 56 (1): 6-12.

[35]. Vrangbaek K, Østergren K, Brik HO, Winblad U: Patient reactions to hospital choice in Norway, Denmark and Sweden. Journal of Health economics, policy and Law1999; 3:47-110.

[36]. Grant TC: Patient Satisfaction with Inpatient Services at the National Referral Hospital of Belize. Master Thesis, School of Health Care Administration, Taipei Medical University 2012; 7(3):118-140.

[37]. Ramamohan D, Saikumar K: A Study on The Satisfaction Of Patients With Reference To Hospital Services. International Journal of Business Economics \& Management Research.2011; 1(3):48-90.

[38]. Boadu F: An Assessment of Consumer Care and Satisfaction in Government Healthcare Institutions in Ghana - The Case of Juaben Government Hospital. Thesis, Institute Of Distance Learning, Kwame Nkrumah University of Science and Technology2011; 4(3):34-68.

[39]. Bashir T, Akmal S, Khilji BA, Bashir R: Study of Patients Satisfaction and Hospital Care in Pakistan: Case Study of Madina Teaching Hospital University Faisalabad. World Applied Sciences Journal2011; 12(8): 1151-1155. 